\title{
THE WALWORTH ALTERNATIVE: RETAINING AND ENHANCING BRITAIN'S SOCIAL HOUSING ESTATES UTILISING CONTEMPORARY TIMBER CONSTRUCTION
}

\author{
Mike Kane ${ }^{1}$ and Ron $\mathrm{Yee}^{2}$
}

\section{INTRODUCTION}

This paper describes the research designs of London South Bank University (LSBU) Masters of Architecture students who investigated the future housing needs of expanding cities, focusing in detail on the Walworth area of South London as a potential model for application elsewhere. The students then proposed innovative ideas on how to expand and remodel the Aylesbury Housing Estate through the use of contemporary timber construction without resorting to wholescale demolition.

The study is part of ongoing research into resource efficient architecture and planning by the M. Arch - Resource Studio 22 tutored by Mike Kane and Ron Yee at LSBU. The field of study was inspired by the Metsäwood's Plan B research program of case studies on iconic buildings, such as the Empire State Building in New York and the Colosseum in Rome, that re-engineered them in timber. (a) During the study period LSBU with the support of Metsäwood organised the "Urban Wood" seminar where 3 renowned architects were invited to speak about building advanced engineered timber buildings within dense urban London locations.

\section{KEYWORDS}

contemporary timber construction, resource efficient architecture, sustainable cities, London housing

\section{FUTURE LONDON}

The recent densification of many 'world cities' is commonly driven by an expanding residential demand caused by an explosion in population growth. Often, this results in the 'old city' being replaced or expanded outwards with super-dense developments which universally disregard any relationship with location, climate or local culture. Without exception, this global phenomenon requires a paradigm shift from the traditional semi-productive and diverse city to the global mono-cultural consumer-driven city which exploits all its essential resources from a global network of sources and supply chains. Widely used terms such as 'sustainable', 'resilient' or 'eco' cities are a contradiction in terms - as all cities are by their

1. Senior Lecturer, Masters in Architecture London South Bank University, Reg. Arch, \& Director KMK Architects, London.

2. Senior Lecturer, Masters in Architecture London South Bank University, Reg, Arch, RIBA \& Director, Yee Associates, London. With design contributions from : Robert Davidson, Luke Marchant, Mandeep Ryait \& Tom Garton. 
nature consumptive, requiring ever increasing food, material and energy footprints in order to sustain modern city life.

London, like most world cities, has seen this phenomenon of reconfiguring the city based on 'the global consumer model' in many neighbourhoods both inside and around the traditional centre. This financially driven model needs large areas of land which can facilitate wholesale redevelopment and like the post-war eras slum clearances, usually requires the forced relocation of established communities for this to happen. However, unlike the derelict post-war bomb damaged plots, these London sites are now primarily occupied by socially rented housing with an intact community. In fact, these 'estates' were originally built for the people of London to allow it to expand and thrive.

The current provision of housing in London is continually described in the media as 'a housing crisis'. The cause of this 'crisis' has been grossly exacerbated by the recent rapid rise in property prices, along with other factors such as a global international investment shift into property, the availability of low interest capital, and a lack of housing supply for an increasing urban population.

Walworth is to the South of Elephant \& Castle and is within walking distance of both the City of London and Westminster, and has fast public transport connections to the burgeoning financial district of Canary Wharf. Historically, the Walworth area was a working class district of social and private rented housing with many small scale artisanal workplaces and a vibrant street culture dating back to Roman times.

Following both World Wars, large scale social housing infilled the derelict and vacant sites. For the most part the original street patterns remained with some exceptions such as the Heygate and Aylesbury Estates. Exacerbated by long term public subsidy cutbacks, and a lack of necessary investment, a social and physical decline in housing conditions developed, and the estates became less attractive and costly for Southwark Council to maintain. This led to the council proposing a wholesale redevelopment of both estates, despite an overwhelming community vote to refurbish rather demolish. Both estates are currently undergoing a rapid and radical change in unpopular housing provision which has resulted in community protests, acts of resistance and legal actions resisting the privatisation of its social housing. The Heygate Estate comprised of 1,194 social rented homes has now been demolished - only to be replaced by 2,500 new units primarily for sale, with provision for just 74 social rented homes. The neighbouring Aylesbury Estate comprised of 2,700 residential units at its peak is also going through a phased demolition as part of an ongoing process of 'regeneration'.

Despite the lack of investment in housing, the public life of the area has thrived. Walworth is an ethnically mixed, mainly working class community that has managed to maintain a living urban heart. The street markets and social life of the area are, in many ways, more vibrant than most areas of London and its rich mix of cultures adds to the diversity that cities like London need. Many have commented on this aspect of Walworth and writings by authors

such as Suzanne Hall of the London School of Economics, illustrate the social necessity of such neighbourhoods more fully. (3)

\section{URBAN WOOD}

Organised with the support of Metsäwood, the Urban Wood seminar was one element of an ongoing programme of study for the 'Walworth Alternative' research programme within the LSBU Architecture School. Three renowned London Architects were invited to speak about 
FIGURE 1. During the research period LSBU organised a public seminar "Urban Wood" with the support of Metsäwood UK Ltd that showcased and discussed recent and planned housing proposals that champion the use of engineered timber construction.



\section{URBAN WOOD:}

\section{An Alternative Architecture}

An event and debate hosted by LSBU Architecture
in collaboration with Metsä Wood

with Alex de Rijke (dRMM), Andrew Waugh (Waugh Thistleton), and Jon Broome (Jon Broome Architects) \& Frank Werling (Metsawood)

Wednesday 2 March 2016, 5.30-8.30pm
debate starts at 6.30

Keyworth Centre lobby + Event Theatre

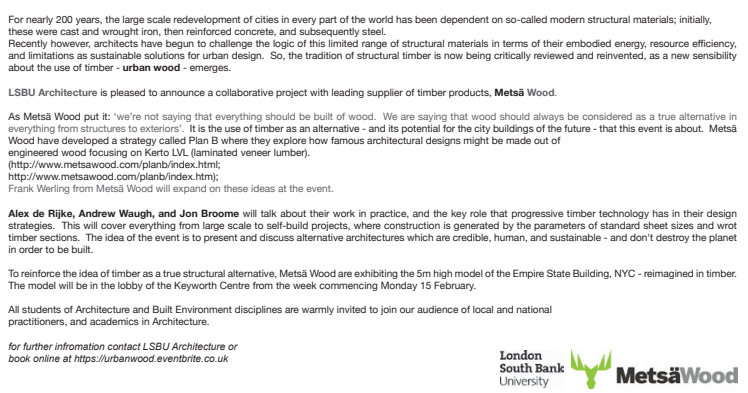

building advanced engineered timber buildings within dense urban locations in London. The purpose was to discuss and expand on the potential for tall timber structures utilising newly developed timber technologies such as CLT (cross laminated timber) and LVL (laminated veneer lumber). Andrew Waugh (Waugh Thistleton Architects), Alex de Rijke (dRMM Architects) and Jon Broome (Jon Broome Architects) along with Frank Werling (Structural Engineer from Metsäwood UK) presented, and Mike Kane (Senior Lecturer LSBU) chaired the event. Several built and potential design projects were presented with the aims of sharing experiences and real-world research of dense urban timber buildings potential for creating a more sustainable city.

Key examples of built and design works presented by the Architects were:

\section{DRMM'S WOODBLOCK HOUSING}

dRMM's Woodblock Housing which has been described as "a revolutionary new housing typology that has the potential to significantly speed up the delivery of new housing, and make it affordable to people of all ages and incomes. Utilising prefabricated CLT panels, as a pre-fabricated, dry-trade material, it is much quicker to build with and less disruptive in urban situations, plus it is a carbon hoarding material with added insulation value". (4) 
FIGURE 2. dRMM's Woodblock Housing is described by its architect as "a revolutionary new housing typology which has the potential to significantly speed up the delivery of new housing, and make it affordable to people of all ages and incomes." image courtesy dRMM.
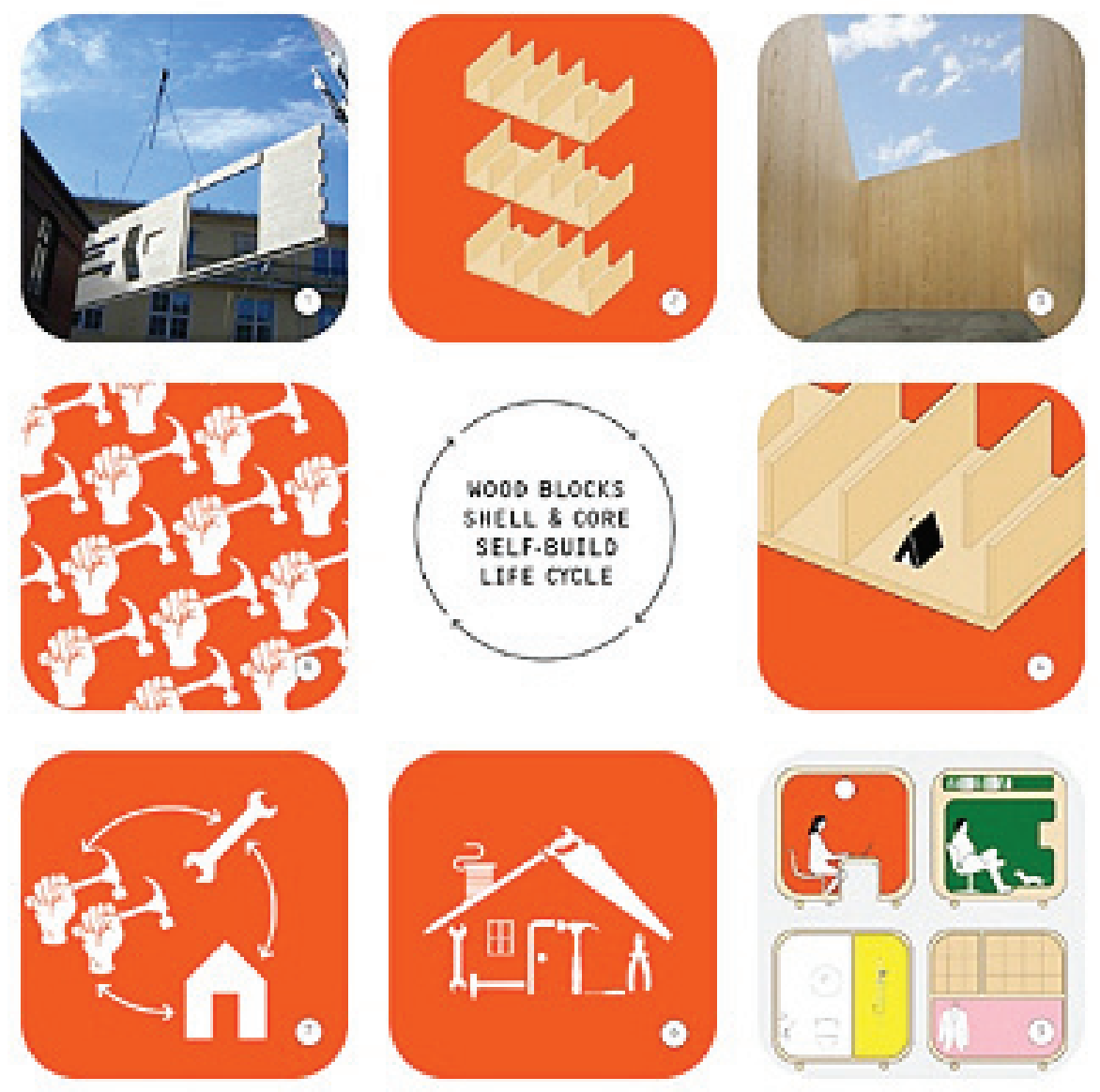

\section{WAUGH THISTLETON'S MURRAY GROVE HOUSING}

This is the first urban housing project to be constructed entirely from pre-fabricated solid timber, from the load bearing walls and floor slabs to the stair and lift cores. Completed in 2009 within 49 weeks, and delivering 29 fully insulated and soundproof apartments, the project successfully demonstrated CLT to be a financially viable, environmentally sustainable and beautiful replacement for concrete and steel in high-density housing. (5)

\section{JON BROOME'S WORK WITH THE SEGAL SELF-BUILD PROJECTS IN LEWISHAM.}

The Lewisham timber framed self-build programme is legendary in establishing a coherent and architecturally rigorous approach to housing in London for unskilled people to build their own houses on sites around South London. In 1985 the programme completed many houses utilising a sophisticated yet simple system of standard building components. The primary timber frame structure and other components were capable of being fabricated and built with little need of external specialists or machinery. (6) The simplicity of the elegant system has been compared to the traditional Japanese domestic house. 


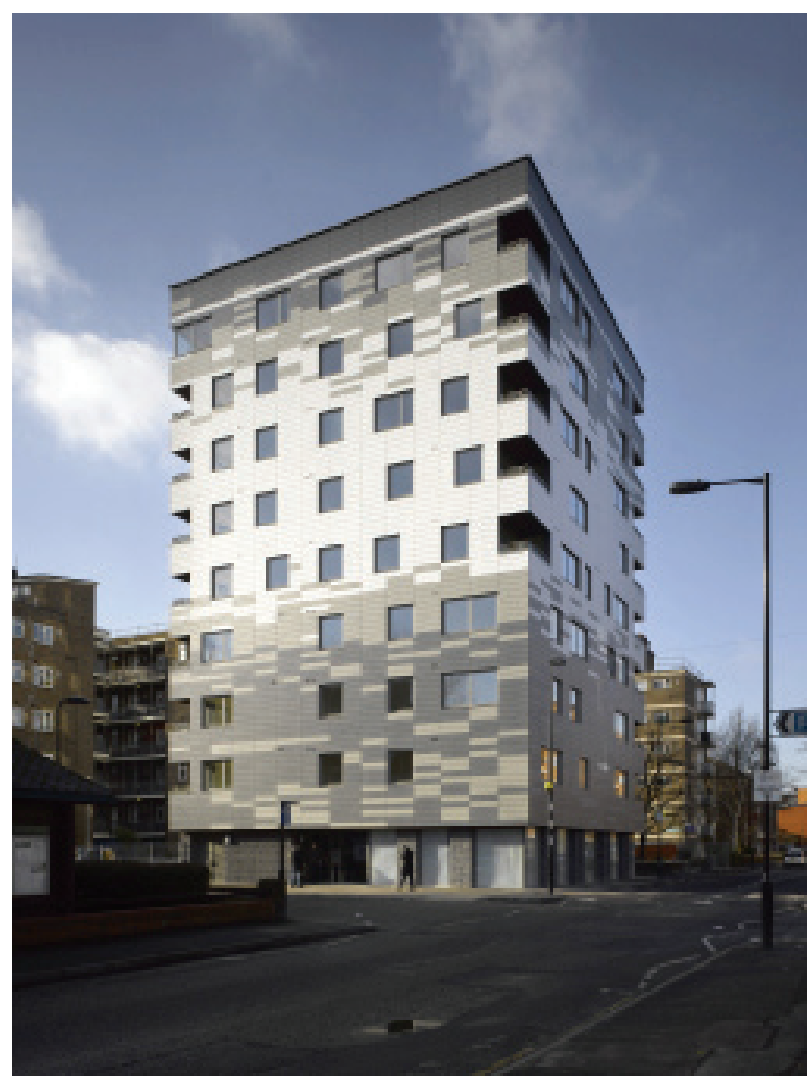

FIGURE 3. Murray Grove housing - The UK's first urban high rise housing project to be constructed entirely from pre-fabricated solid timber.Image courtesy Waugh Thistleton, photo: Will Pryce.

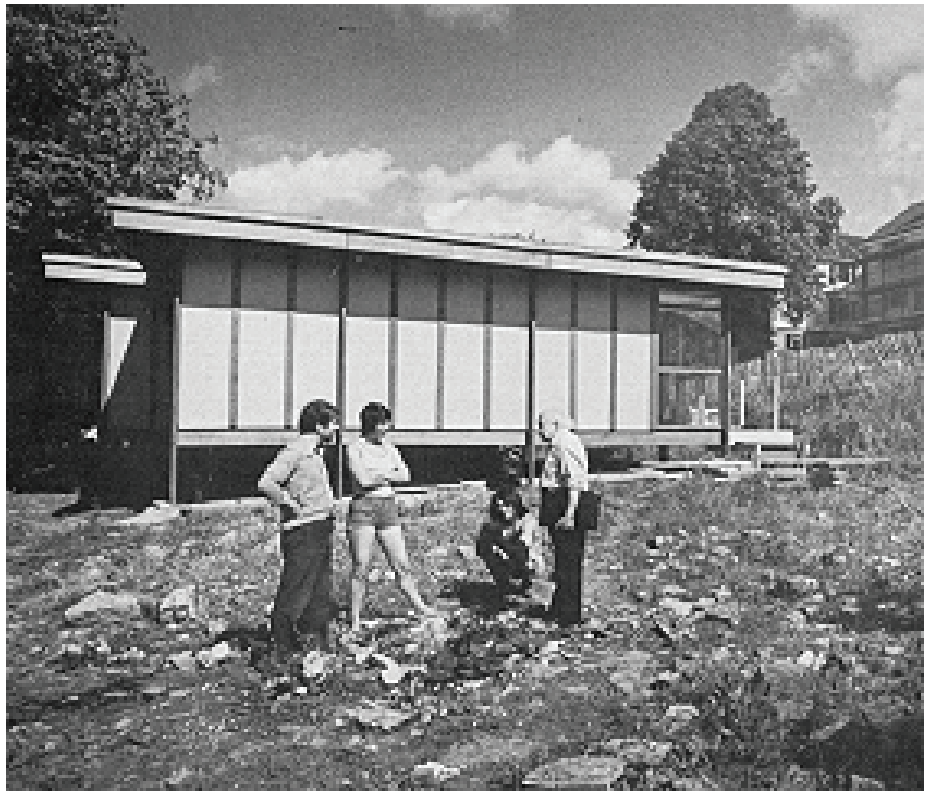

FIGURE 4. The design of Walter Segal's Self Build Project in Lewisham has been compared to the Japanese domestic house.

Discussion following the presentations raised many issues on the potential and advantages of timber construction in the city. Despite these obvious advantages, all agreed that the real advantages of high density (and often tall) timber buildings had yet to be fully realised. The construction industry is particularly slow to adapt to newer techniques and misconceived prejudices are a significant barrier to the use of timber as a structural material. However, as more engineered timber buildings are completed, the technology will likely become more 
standard, given its key advantages in cost, time and ease of construction. One important aspect to architects and designers is that engineered timber offered new ways of designing. The comparison with the first steel frame building (The Home Insurance Building, Chicago, by William le Baron Jenney 1884) still used the architectural styles of masonry construction, despite it being a steel building. In the case of timber, CLT and LVL are still relatively recent advances in building technology and therefore have yet to be fully understood as new way of building and designing.

\section{RESEARCH \& DESIGN: FUTURE WALWORTH}

The focus of the initial research was on exploring ways in which living in the city can become less reliant on consuming energy and food and material resources from increasingly distant sources. Cities typically originated in places because they had local or easy access to all these resources; however, this is not the case in the majority of recently expanded world cities. Both the physical and social context of the existing city is considered to be a positive asset to be enhanced. Walworth is used as a potential model for other world cities, bearing in mind that essential local particularities may make a universal single solution inadvisable.

To clarify the focus of the studies it is necessary to first describe the prevalent model of urban development where an 'Estate' is sold off by a Council either in total or as parcels to a selected Developer. In the case of the Heygate Estate, Southwark Council chose the global property giant Lendlease Group and the entire estate was sold at an eventual loss, after accounting for the costs of decanting it's 3,000+ residents and site clearance. The new housing, planned with drastically intensified density and designed to reduced space standards, is intended mainly for sale on the open market making it likely that none, or very few, of the original residents will have the opportunity to return. Despite many legal and political challenges, including numerous protests against the sale at all levels, the sale proceeded and demolition is now complete.

The original Aylesbury estate was completed in 1974, along the lines of the international style' modernist housing blocks typically found all over Europe and the developed world. Following recent surveys, the majority of the estates concrete construction was found to be structurally sound and the buildings proven capable of remodelling, and this was the communities preferred option.

\section{Research was based on the following parameters:}

1. Existing residents \& communities should be supported, enhanced and expanded.

2. Existing structures should be retained and refurbished, with additional structures in timber where possible.

3. Additional housing should be provided, due to the current housing needs of a city.

4. Assuming the property remains in the ownership of the council, any new housing should be at affordable social rents.

5. Provision for growing food is paramount, and should be integral to the design of both individual and shared landscapes.

6. Special consideration should be focussed on the carbon footprints of proposals and how this can be minimised. Existing structures should be retained in order to reduce the impact of energy requirements due to construction materials, fabrication and distribution. 
FIGURE 5. Built between 1963 and 1977 the Aylesbury Estate located in Walworth, South East London contains 2,704 dwellings with approximately 7,500 residents.

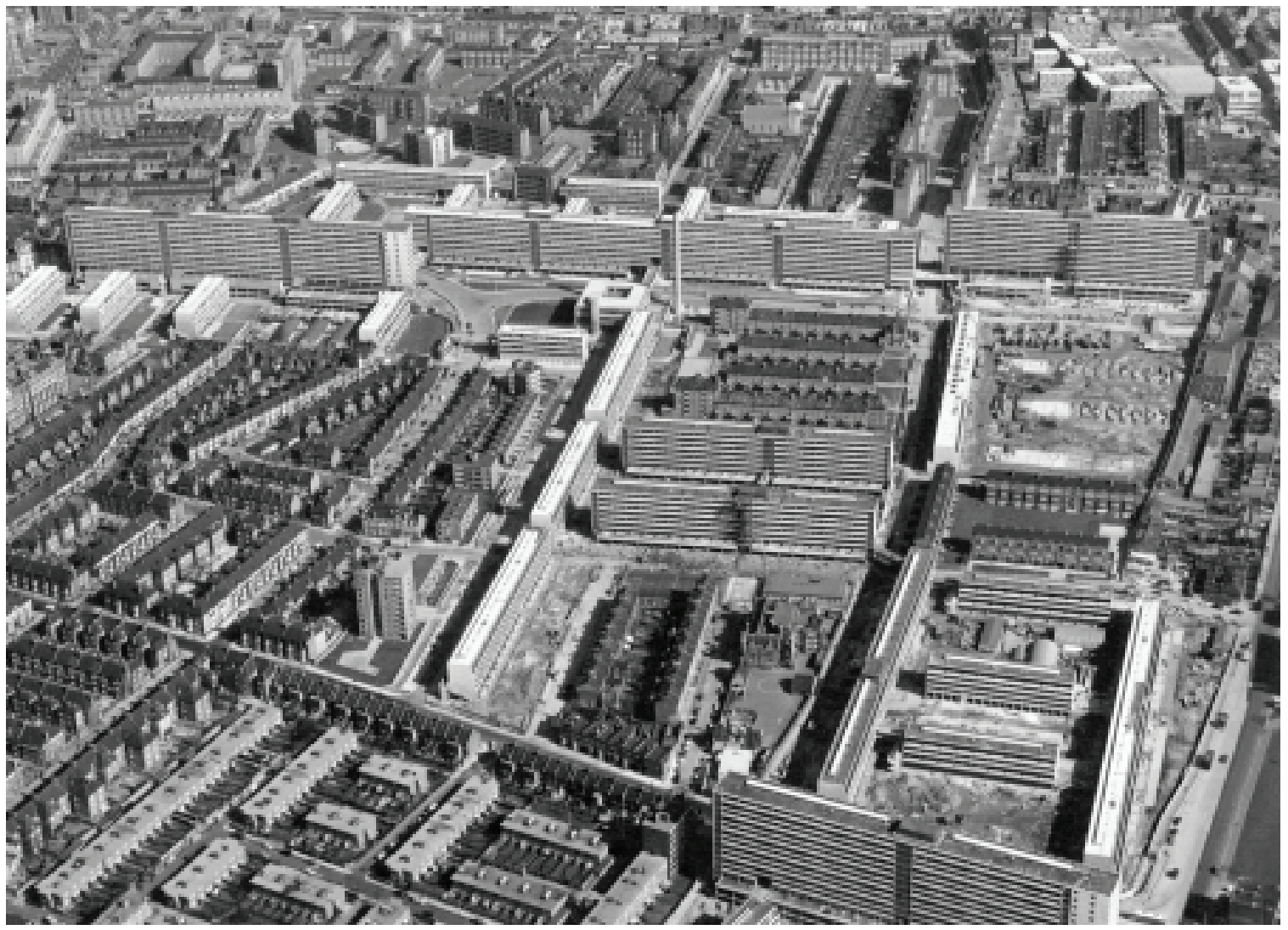

\section{STUDENT PROTOTYPES:}

For the purpose of this paper, four key building scenarios have been selected to illustrate the potential alternative approaches. They illustrate a variety of solutions to provide an inclusive and productive alternative to the 'consumptive city'.

FIGURE 6. Type A: The large urban slab block - Chiltern House, Portland Street, London SE17 2DE.




FIGURE 7. Type B. Open green landscaped buildings with allotments - Brisbane House, London SE5 7NG.

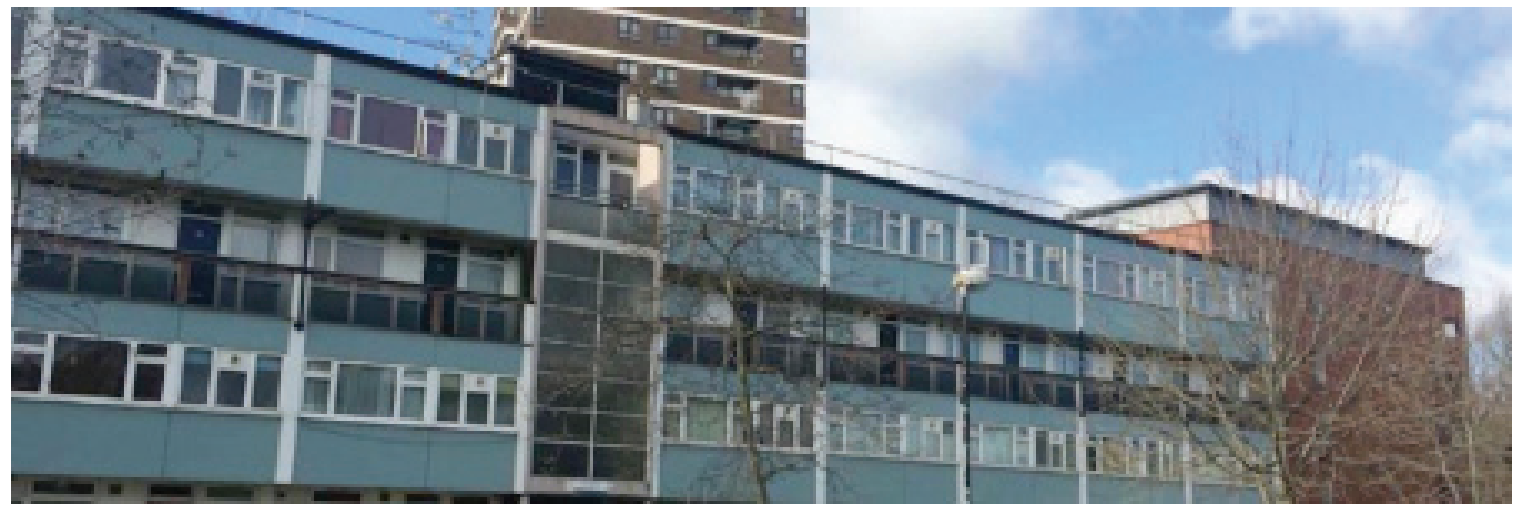

FIGURE 8. Type C. A landscaped cluster of 3 small housing blocks - Elmington Estate, London SE5 7HU.

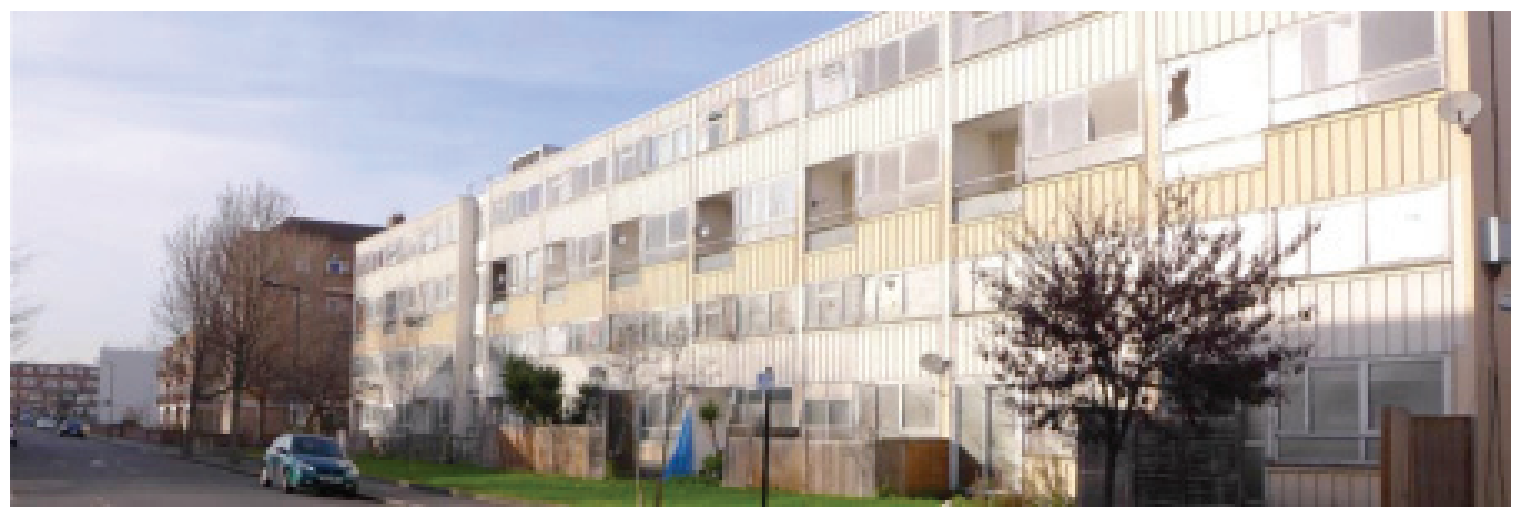

FIGURE 9. Type D. Elongated terrace housing - Gayhurst House, Aylesbury Estate SE17 2BL

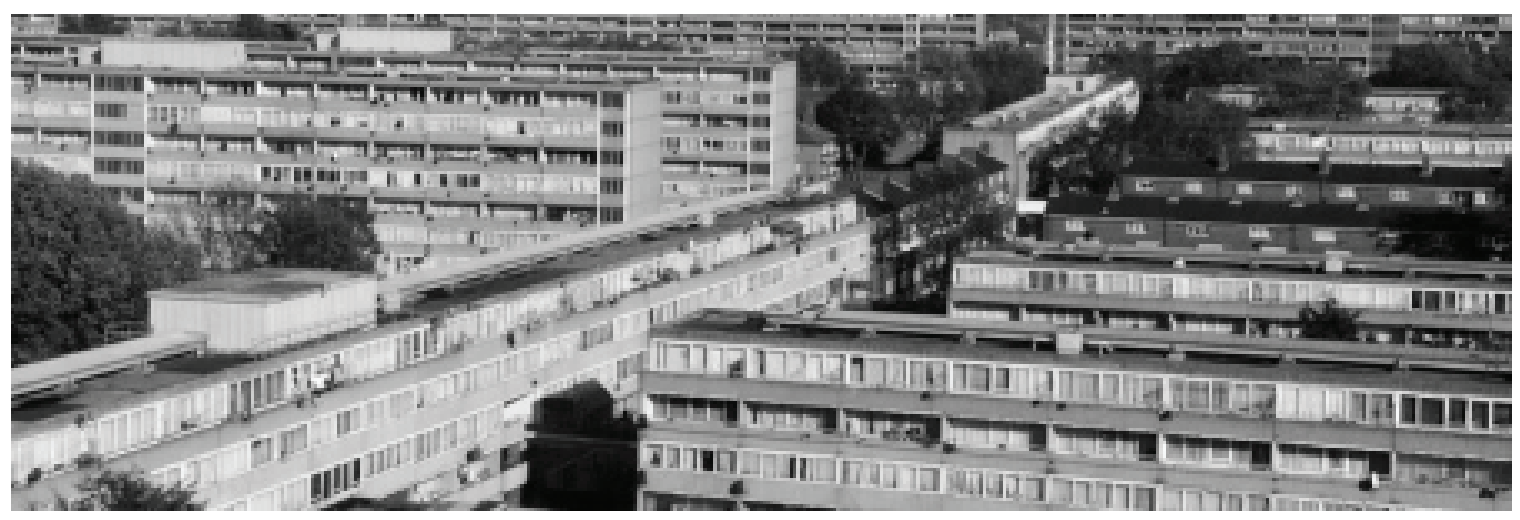

\section{EXAMPLE A: CHILTERN HOUSE, PORTLAND ST, LONDON SE17 2DE LUKE MARCHANT}

Chiltern House is a super scale of slab blocks on the Aylesbury Estate, with a north south orientation, on the northern edge of Burgess Park. At fourteen storeys high and over $200 \mathrm{~m}$ long, it is one of seven blocks that are evenly distributed across the estate. The carbon cost 
of constructing this building was extremely high. The reinforced concrete structural frame (excluding partition walls and internal elements) is estimated to weigh in excess of 20,000 tonnes which equates to approx. 1,800 tonnes of emitted $\mathrm{CO}_{2}$ for the concrete alone. This figure is significantly increased with the remainder of the construction process and transport emissions. Demolition of Chiltern House requires in the region of $800+\mathrm{HGV}$ truck journeys through London's congested streets, and the use of heavy demolition machinery will greatly

FIGURE 10. Chiltern House is one of seven slab blocks on the Aylesbury Estate.
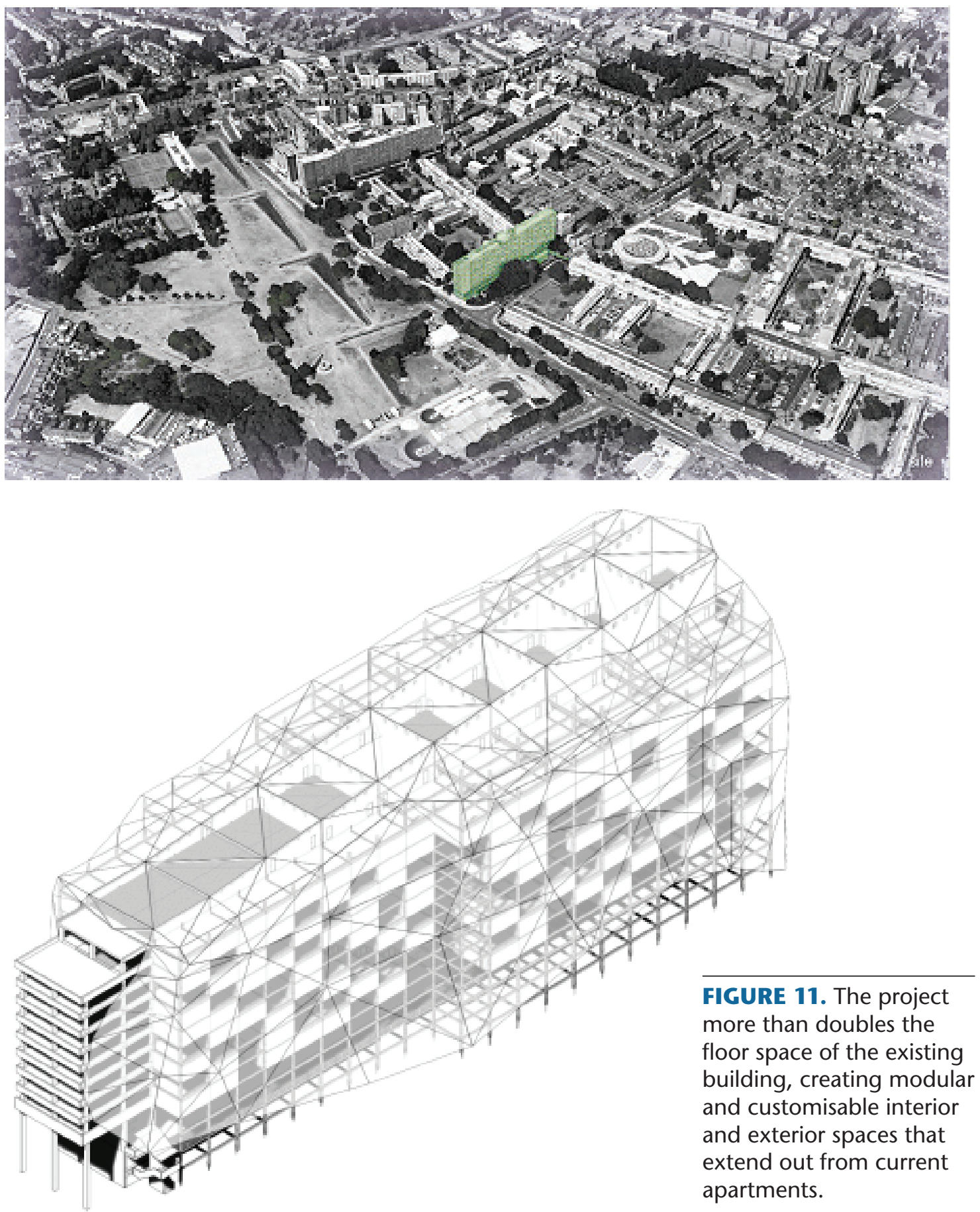
add to the figure again. Clearly, the $\mathrm{CO}_{2}$ emission cost of reaching just the cleared site (after only 40 years of housing use) is very high, moreover, if the replacement building is of conventional construction (with only 30 year warranty), then the overall environmental cost of providing additional homes is enormous.

The project's aim is to create a prototype modular housing system that can be applied to one of the Aylesbury Estate blocks to offer an alternative to the planned demolition. The underlying themes of material efficiency, ease of construction and user customisation draw influence from the Walter Segal Self Build ethos and apply it to the symbiotic rejuvenation of an existing structure. The project more than doubles the floor space of the existing building, creating modular and customisable interior and exterior spaces that extend out from the current apartments.

FIGURE 12. Concept diagram of the proposed new modular extension to Chilton House.

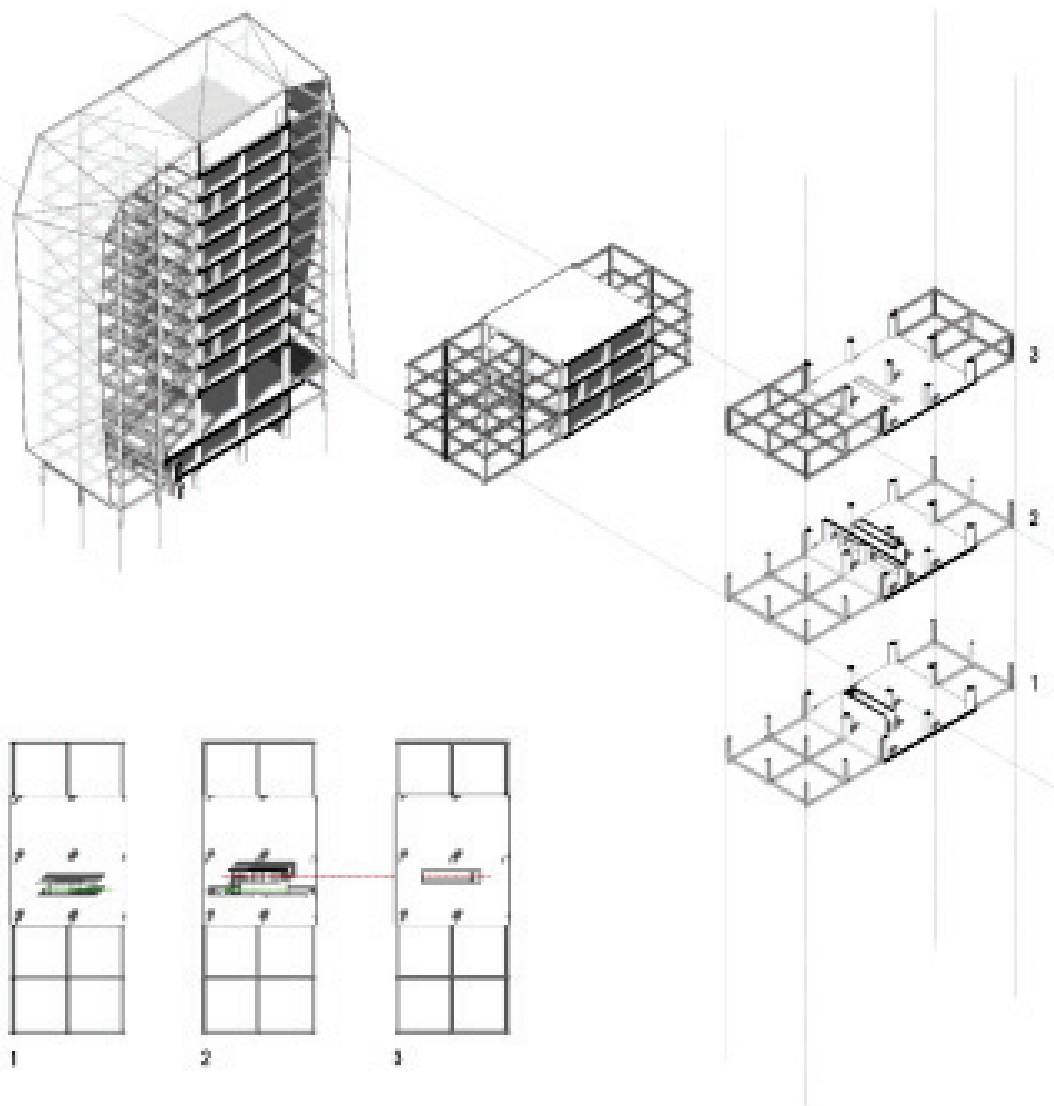

By utilising several passive ventilation systems combined with an external skin that is similar to that employed on the Eden project, varied climactic conditions create cool well ventilated living spaces and warm humid greenhouse areas conducive to producing crops for the inhabitants.

This project focuses strongly on the community to rejuvenate an estate that has been repeatedly demonised by the Government and the tabloid press. The majority of urban buildings have the potential for expansion with lightweight timber extensions which could solve the 
FIGURE 13. Exploded diagram of the Japanese inspired joint detail for the proposed new structural frame.
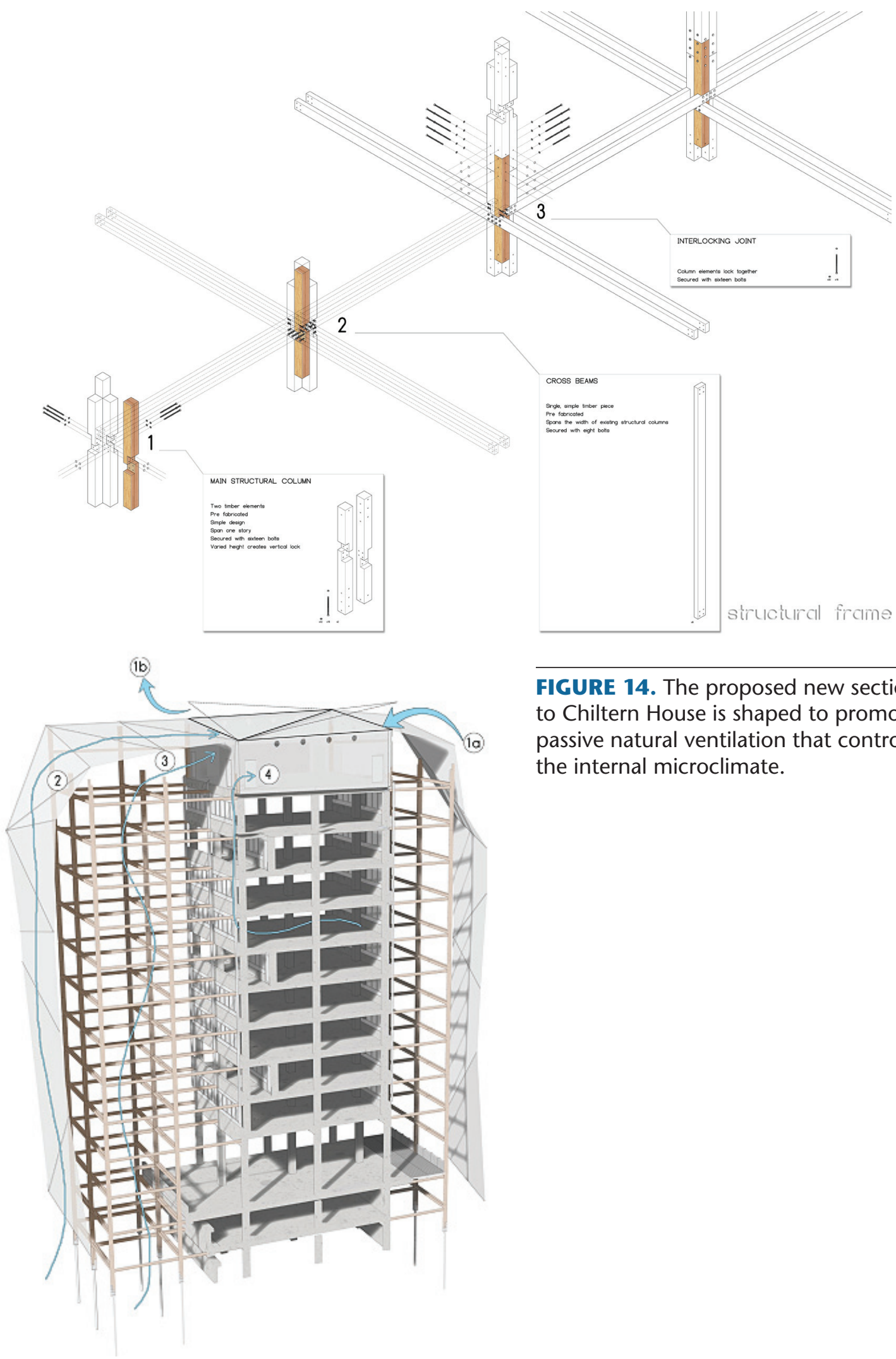

FIGURE 14. The proposed new section to Chiltern House is shaped to promote passive natural ventilation that controls the internal microclimate. 
problems of re-densification whilst improving the quality of life for residents and minimising the additional energy required for construction. By adjusting parameters to match the environment in which scheme is placed, this approach could theoretically be applied anywhere.

FIGURE 15. Rendering of the transformed public realm to Chiltern House. All Chiltern House images courtesy of Luke Marchant.

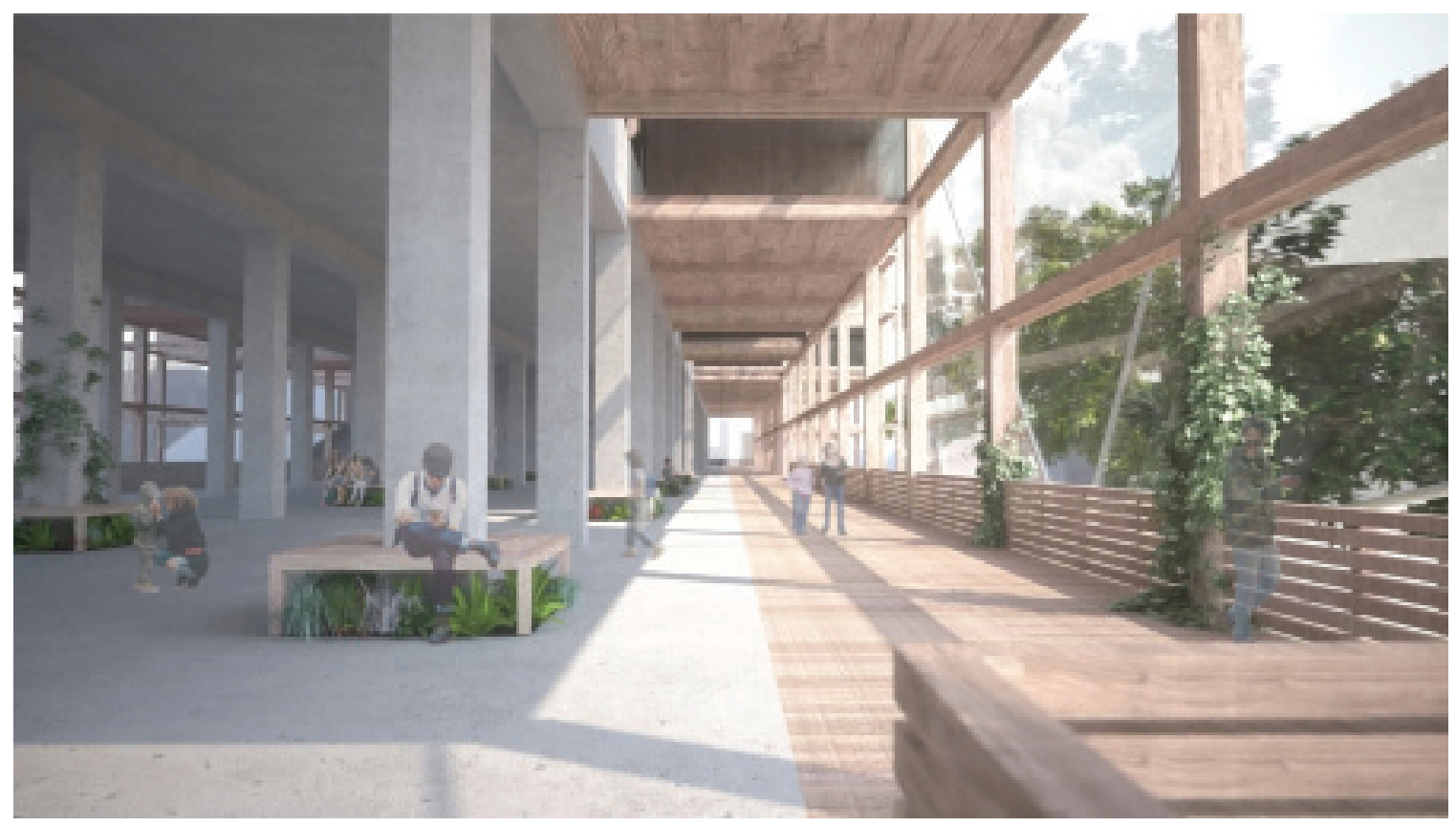

\section{EXAMPLE B: BRISBANE HOUSE \& ALLOTMENTS, LONDON SE5 7NG ROB DAVIDSON}

The 3 blocks of social housing around this site sit within a landscaped area typical of the developments of its time and common through the UK. This particular site is an infill development within the Victorian street pattern of the area south of Burgess Park. Close by are small but well used landscapes of allotment gardens. These types of gardens which are found nationwide provide food within the city, and are extremely popular with the local community, commonly having waiting lists of over 10 years. This scheme extends the allotment concept as an integral part of the housing. Additional apartments in a lightweight timber construction also create gardens within the social circulation spaces enclosed within a 'greenhouse' which extends the productive seasons for growing.

The Proposal aims to be a representation of the socio-economic climate we live in today, especially around the central London area. Forward thinking ideas and good design can also create vibrant living and animated public space for the members of the community to enjoy regardless of a restricted budget. Therefore, this proposal presents an alternative method of construction by using various engineered timber products to provide a solution to the many issues faced across the construction industry within the UK and Abroad. This method saves time and money, allowing for the addition of extra units with increased density on-top of existing structures as timber is far lighter than typical concrete structures. Furthermore, timber construction reduces the impact on the environment by the amount of $\mathrm{CO}_{2}$ that goes into the atmosphere through the nature of the product and the prefabricated design. 
FIGURE 16. Rendering of the transformed public garden to Brisbane House.

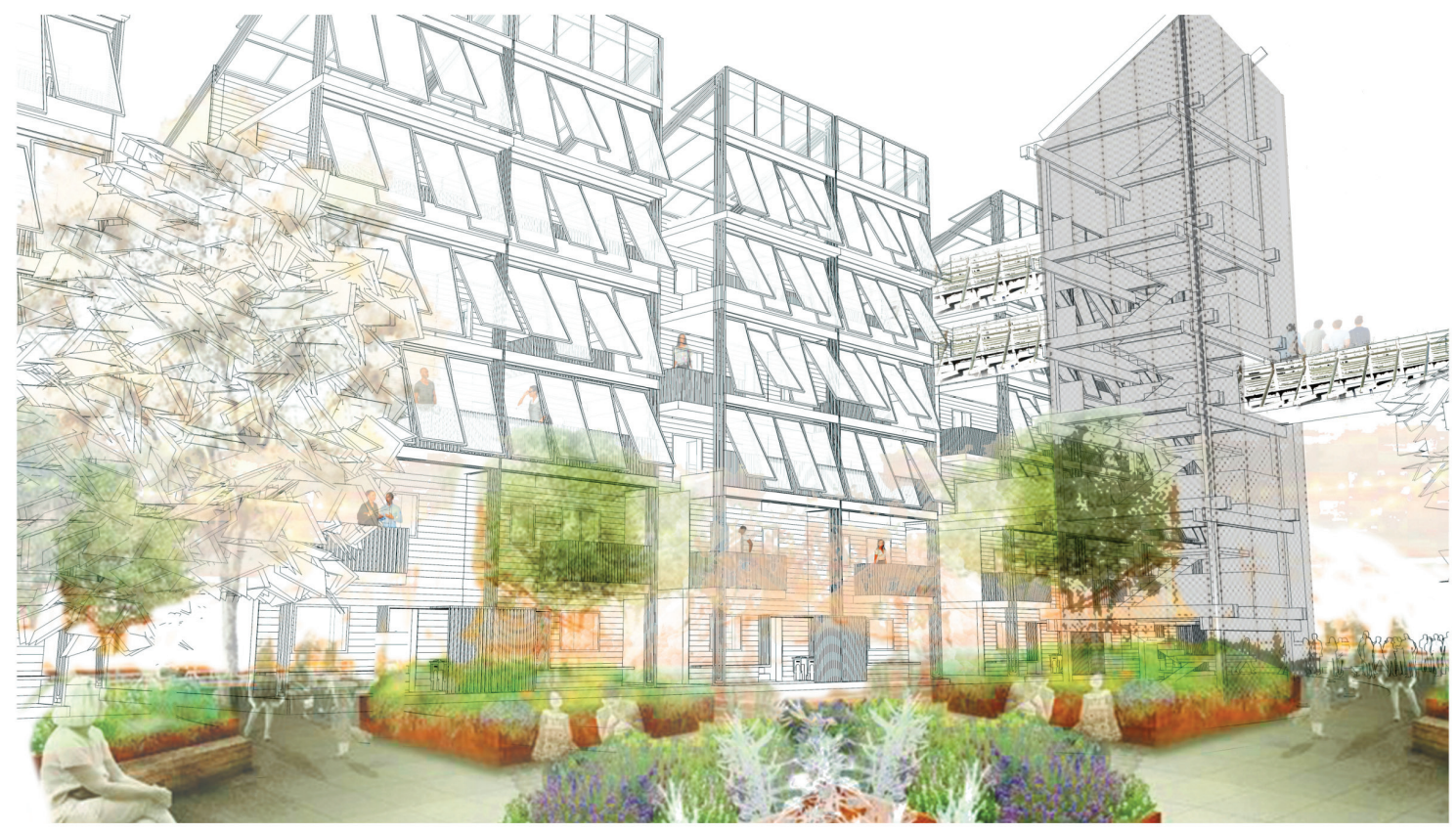

FIGURE 17. Cutaway section of the proposed development of Brisbane House.

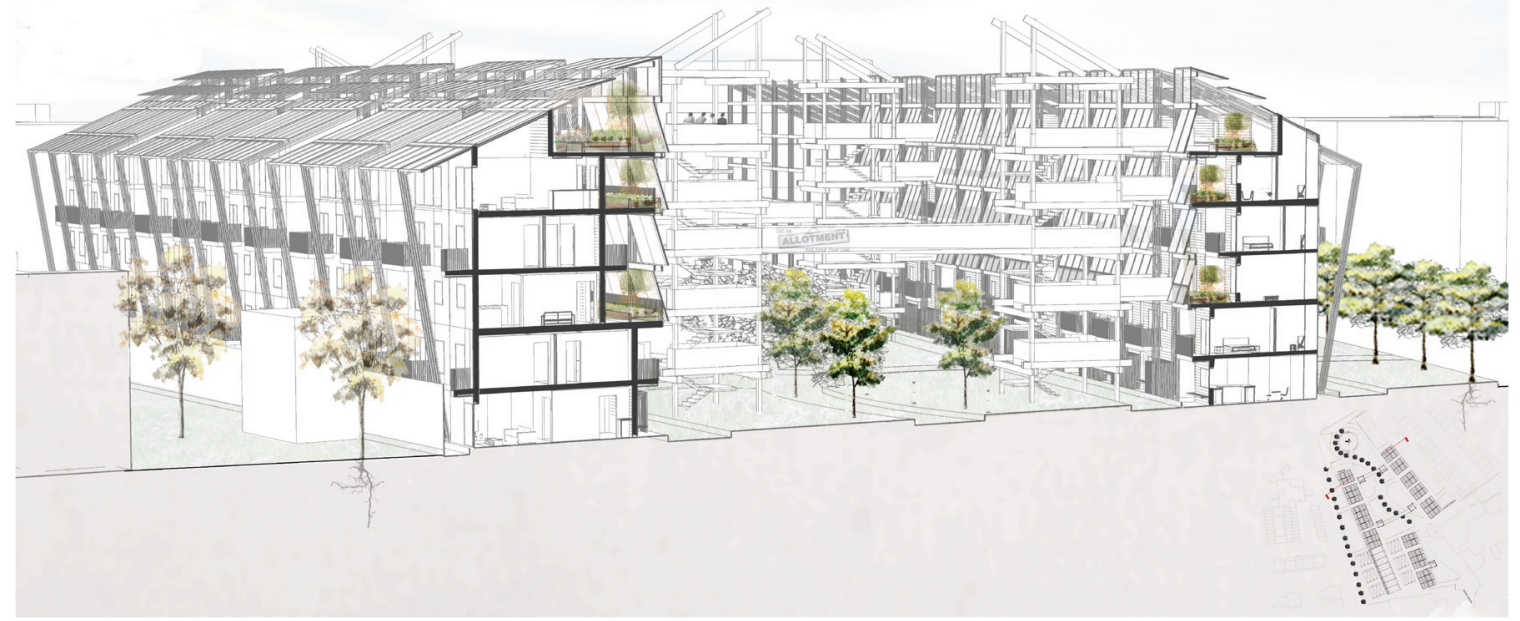

This Project also incorporates new and existing community garden space which will be gardened by residents as a collective, utilizing the shared plots. These Community gardens will provide fresh produce and plants, as well as contributing to a sense of community and connection to the environment with an opportunity for satisfying labour and neighbourhood improvement. It will be publicly functioning in terms of ownership, access, and management. Community Activity will encourage the development to thrive through Events and the nature of the surrounding architecture enclosing the green space to create a warm sheltered outdoor environment. 
FIGURE 18. Detailed section of the proposed new construction to Brisbane House, hinged screens on the façade and openable roof windows enables residents to passively control the internal climate of the community growing space.

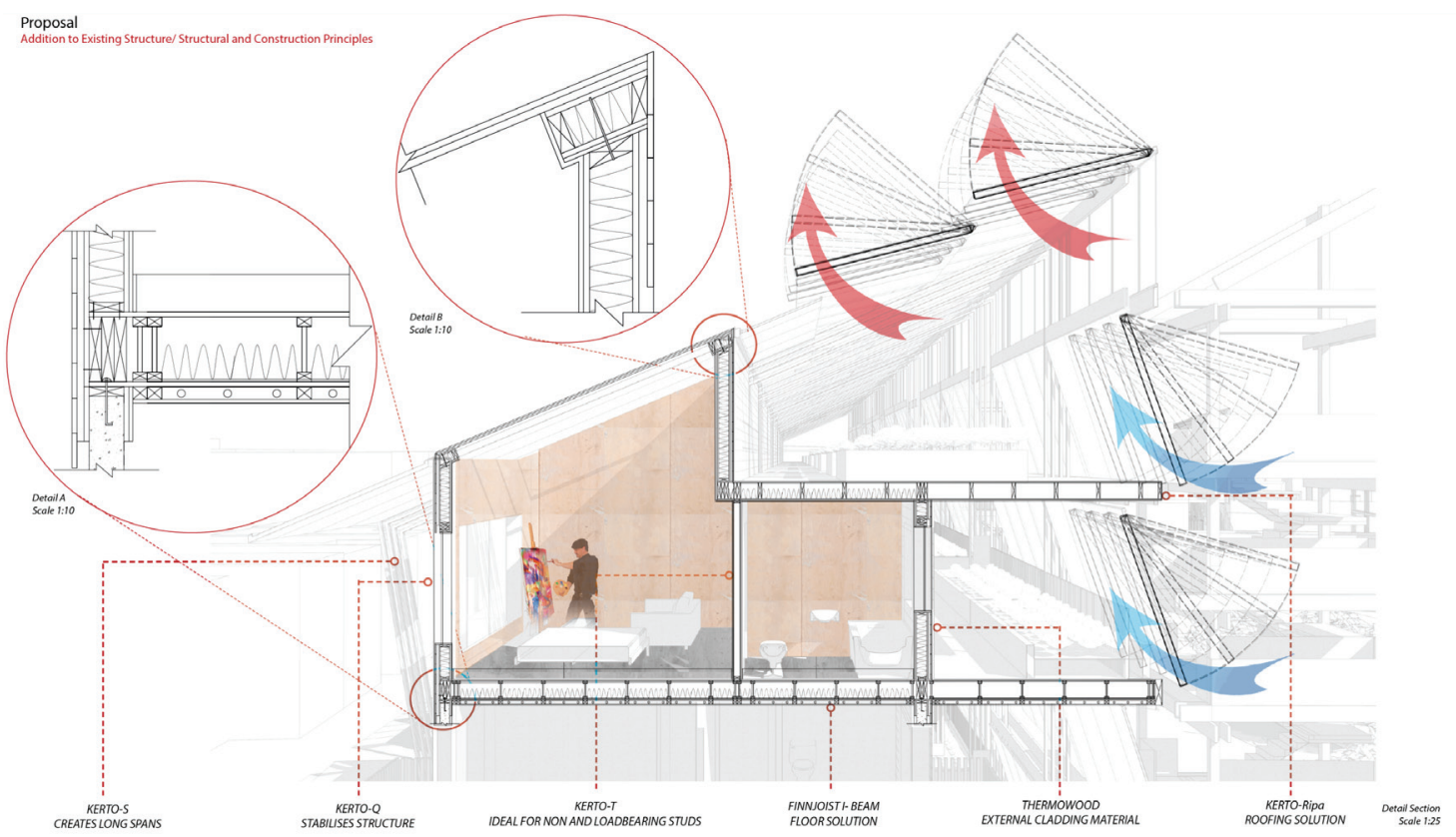

FIGURE 19. Existing internal partitions are removed and replaced with lightweight timber construction.
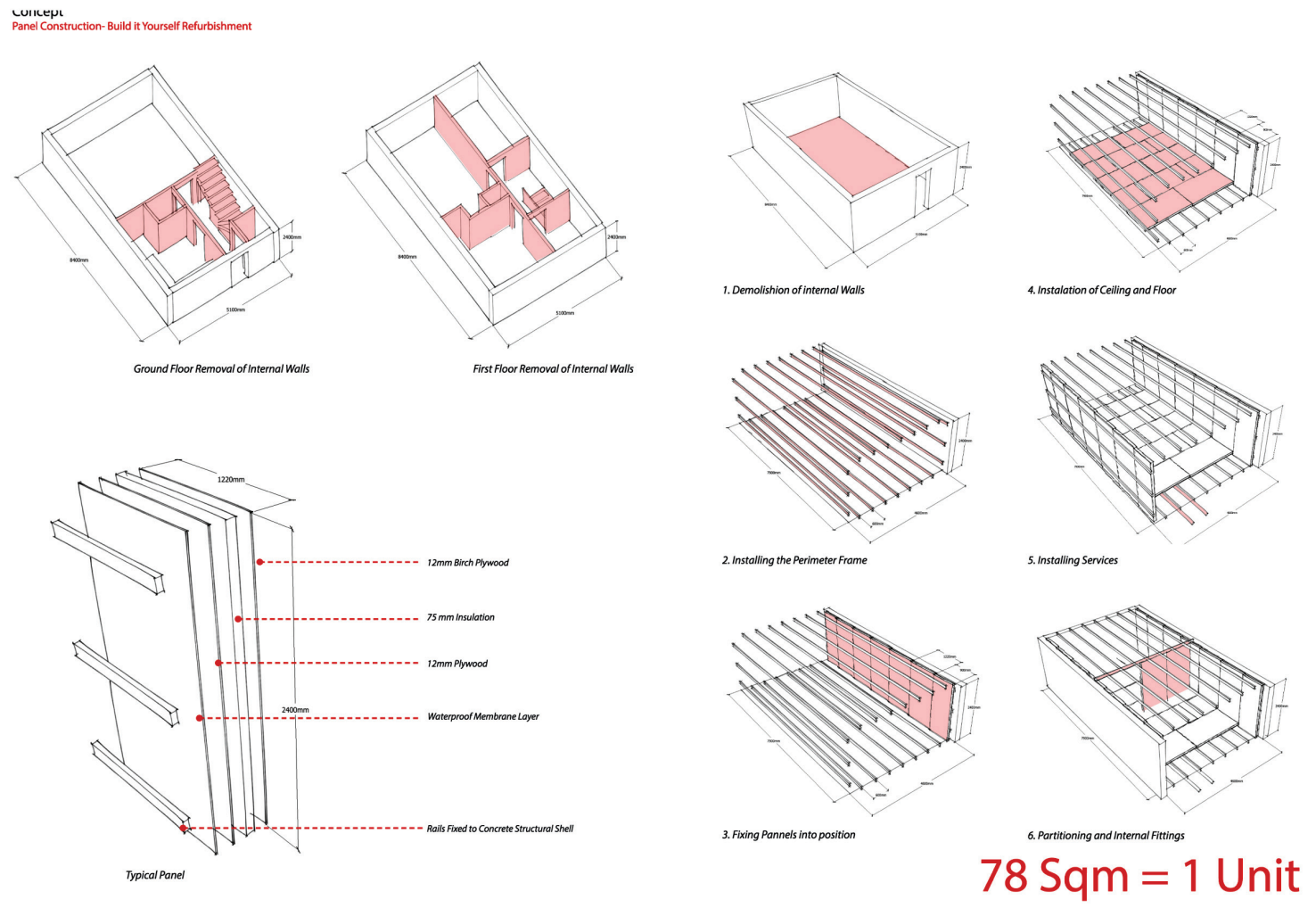
FIGURE 20. Proposed structural components of the alternative redevelopment of Brisbane House. All Brisbane House images courtesy of Robert Davidson.
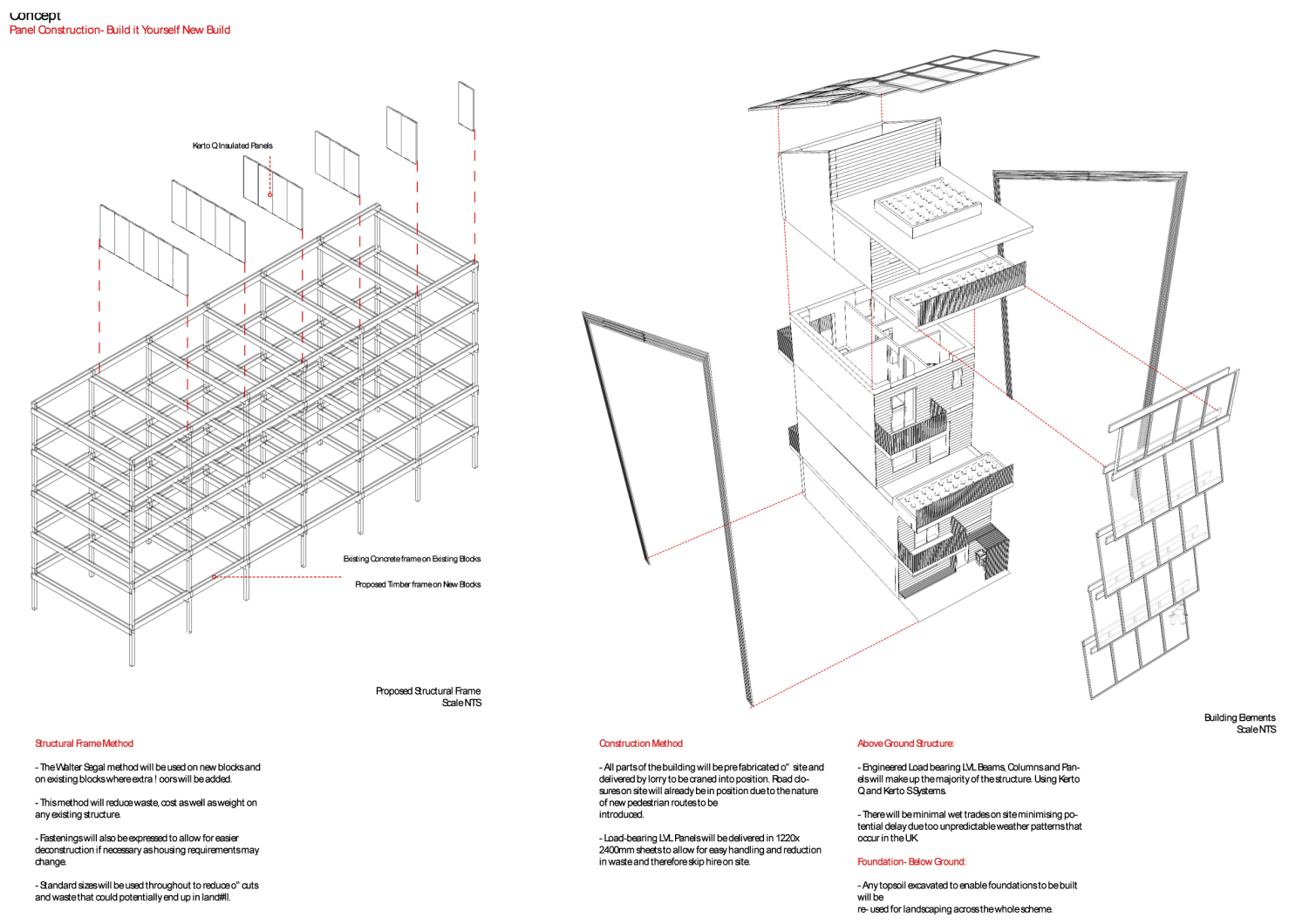

\section{EXAMPLE C: ELMINGTON ESTATE LOW-RISE CLUSTER BLOCKS, MANDEEP RYAIT}

Research is focused on the adaptation of the three housing blocks in the Houseman Way area of Elmington Estate that are currently empty, awaiting demolition to make way for new luxury flats. Elmington Estate is a medium density housing development constructed in 1955 by the London County Council as rented social housing. At that time the higher densities of the later estates had not yet evolved and the Elmington Estate was generously laid out with shared gardens and courts. The buildings are low rise (between 3 and 5 storeys) and were planned to fit in with the existing Victorian street pattern.

Despite being carefully designed, the buildings were poorly maintained and now require significant refurbishment. However, the main reinforced concrete frame is structurally sound and has the capacity to be incorporated into a new development. The greater percentage of green space on this type of estate allows the potential for urban food production. 
FIGURE 21. Rendering of the redeveloped Elmington Estate from street level.

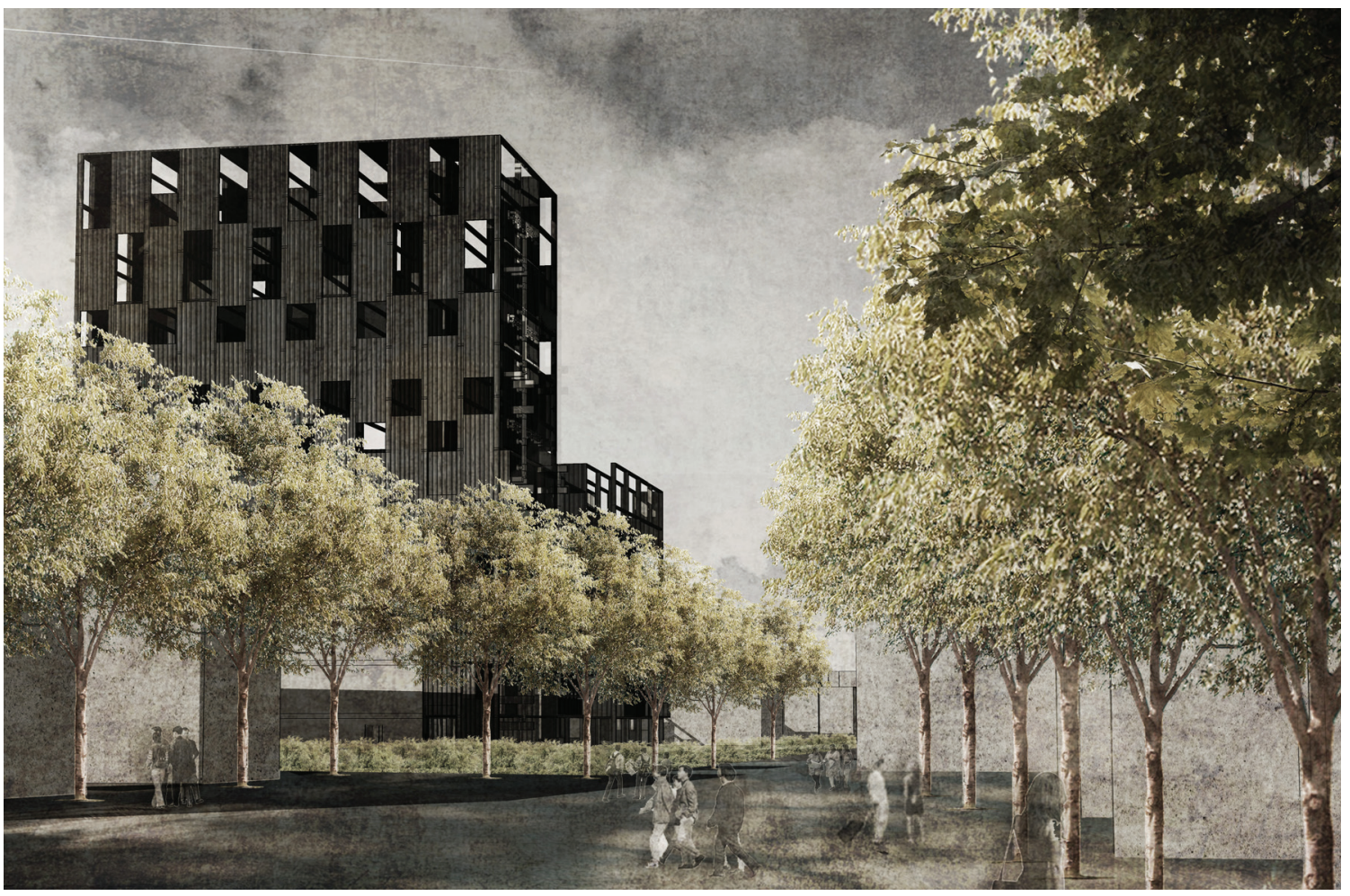

FIGURE 22. Elevation of the proposed redevelopment of Elmington Estate.

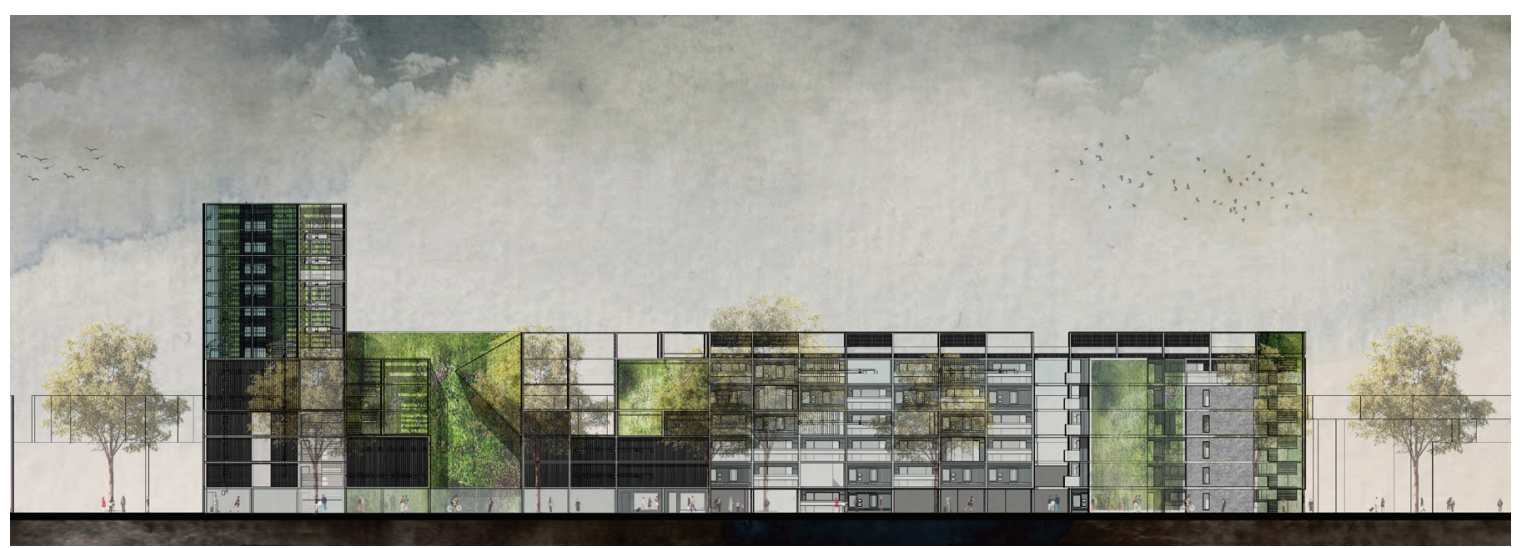






FIGURE 23. Cutaway section of the proposed Elmington Estate. The existing concrete frame is retained and residential units are extended with engineered timber pods.

FIGURE 24. Proposed external envelope components to Elmington Estate.


cross laminated timber fram

solar thermal facade panel

top vent to winter garden to release

warm air

$22 \mathrm{~mm}$ toughened glass to winter garden

seamless joints to all corners

$75 \mathrm{~mm}$ cross laminated timber

planter box clad in charred larch timber

bespoke steel mount housing glazing to

main facade and solar thermal panels

where required

top hung outward opening panel to

purge warm air into the building

bottom hung outward opening panel to

purge cool air into the building

$20 \mathrm{~mm}$ u steel bolted back to concrete

frame and new cross laminated timber

structure

$22 \mathrm{~mm}$ glass balustrade to all balconies

$225 \mathrm{~mm}$ existing concrete floor

$20 \mathrm{~mm}$ steel connecting plate

$75 \mathrm{~mm}$ solid insulation 
FIGURE 25. Assembly diagram of proposed pod additions to Elmington Estate.

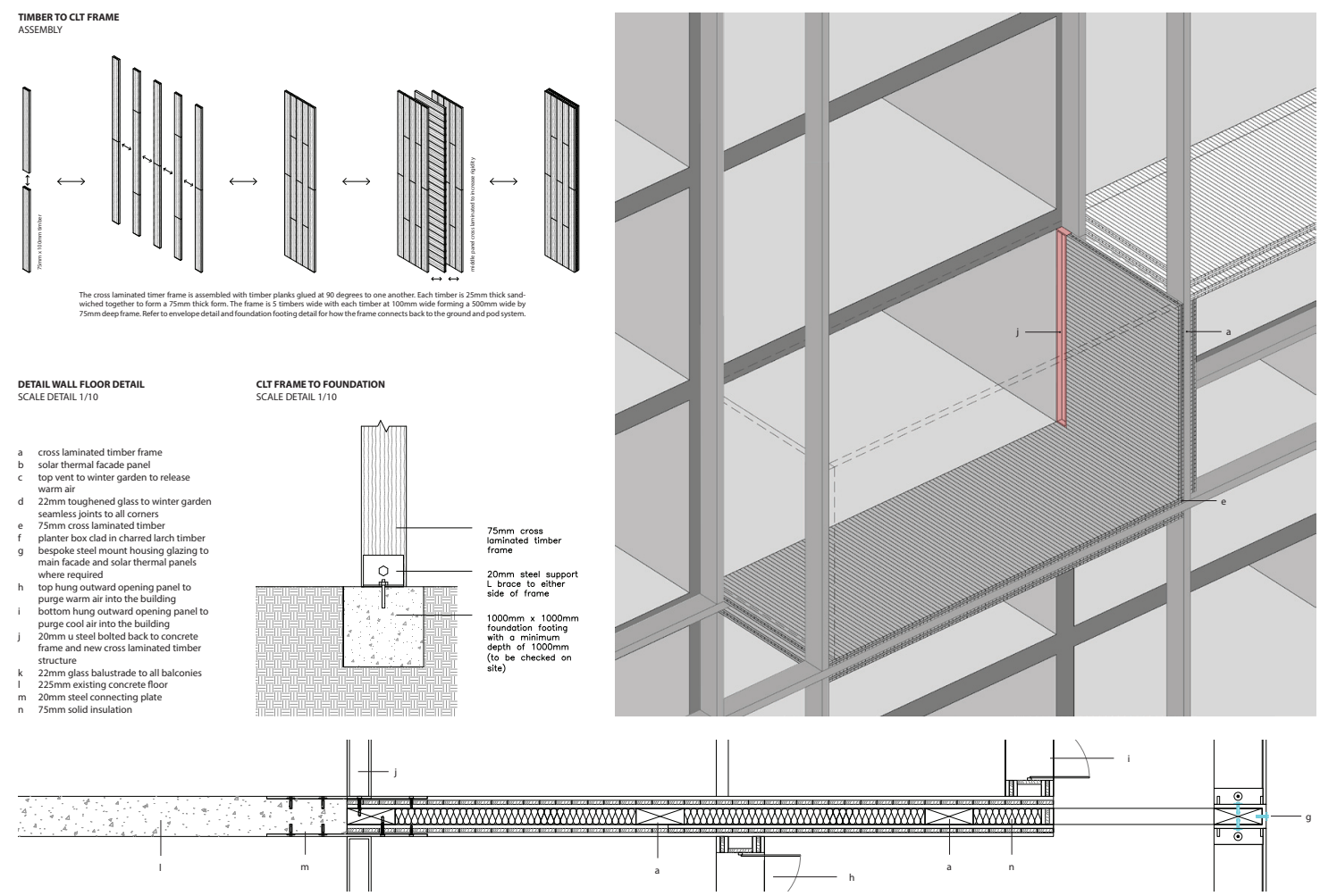

FIGURE 26. Construction detail of the existing wall/timber pod connection.

DETAIL WALL TO FLOOR SCALE 1/10

cross laminated timber fram

solar thermal facade panel

top vent to winter garden to release

warm air

$22 \mathrm{~mm}$ toughened glass to winter garden

seamless joints to all corners

$75 \mathrm{~mm}$ cross laminated timber
planter box clad in charred larch timber

planter box clad in charred larch timber

bespoke steel mount housing glazing to
main facade and solar thermal panels

main facade and solar thermal panels

where required

top hung outward opening panel to

purge warm air into the building

bottom hung outward opening panel to

purge cool air into the building

$20 \mathrm{~mm}$ u steel bolted back to concrete

frame and new cross laminated timber

structure

$22 \mathrm{~mm}$ glass balustrade to all balconies

$225 \mathrm{~mm}$ existing concrete floor

m $20 \mathrm{~mm}$ steel connecting plate

$75 \mathrm{~mm}$ solid insulation




FIGURE 27. Construction detail of the proposed structural frame shoe/footing connection.

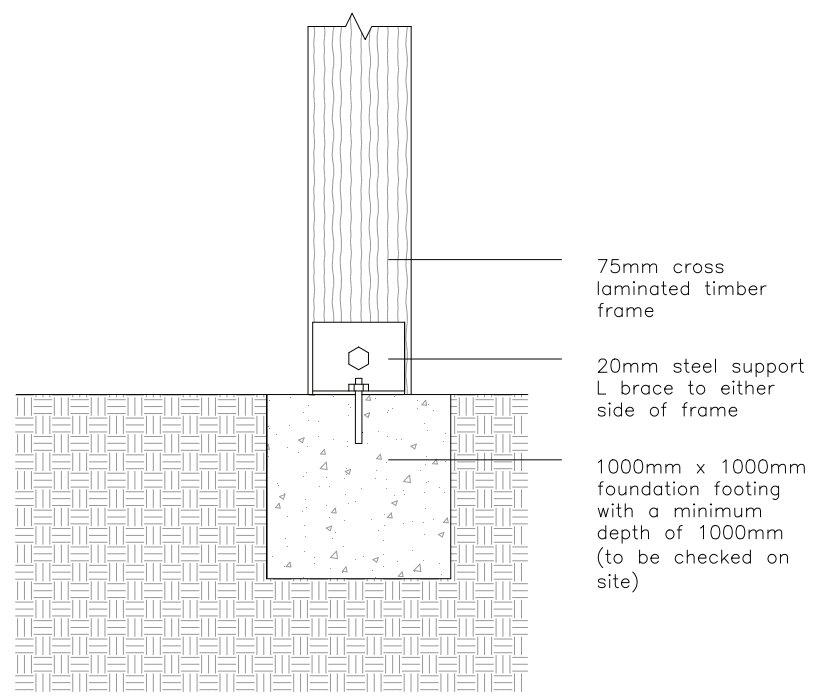

The proposed scheme is to double the housing provision for a sustainable community where food production is central to the design. It retains the primary structure, encasing the building with a timber frame that supports pre-fabricated CLT pods which are inserted back into the main concrete structure - allowing for adaptability.

FIGURE 28. Proposed phased construction minimises disruption of the existing community.
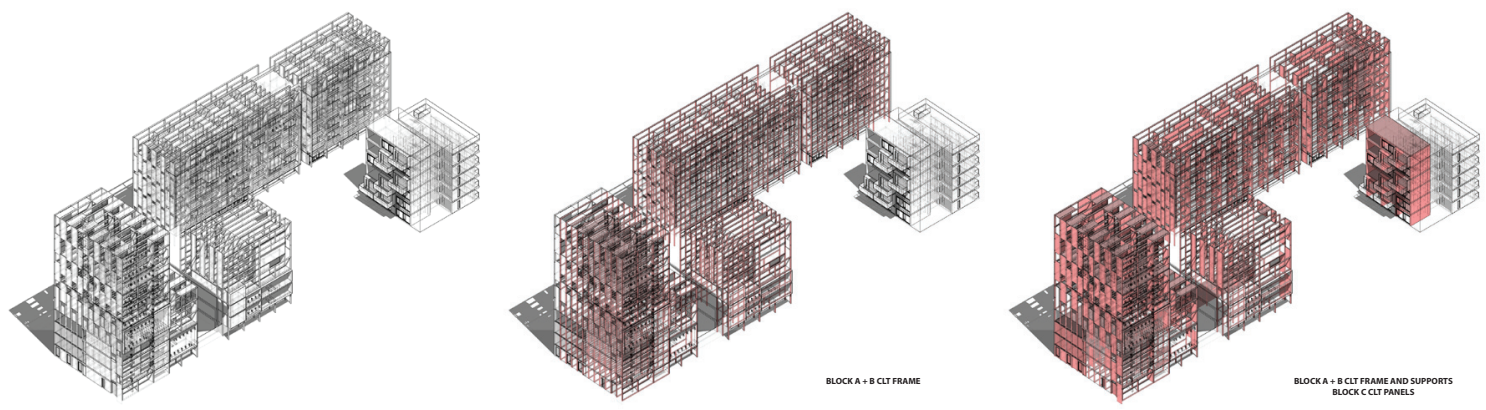

Construction can be phased to minimise disruption to the community by allow existing residents to stay in the area. The concept is not exclusive to Houseman Way but is a prototype system that can be replicated on similar estate blocks. 
FIGURE 29. Elmington Estate lies to the south of Burgess Park. Buildings are low rise (between 3 and 5 storeys) and were planned to fit in with the Victorian street layout. All images of the Elmington Estate project, courtesy of Mandeep Ryait.

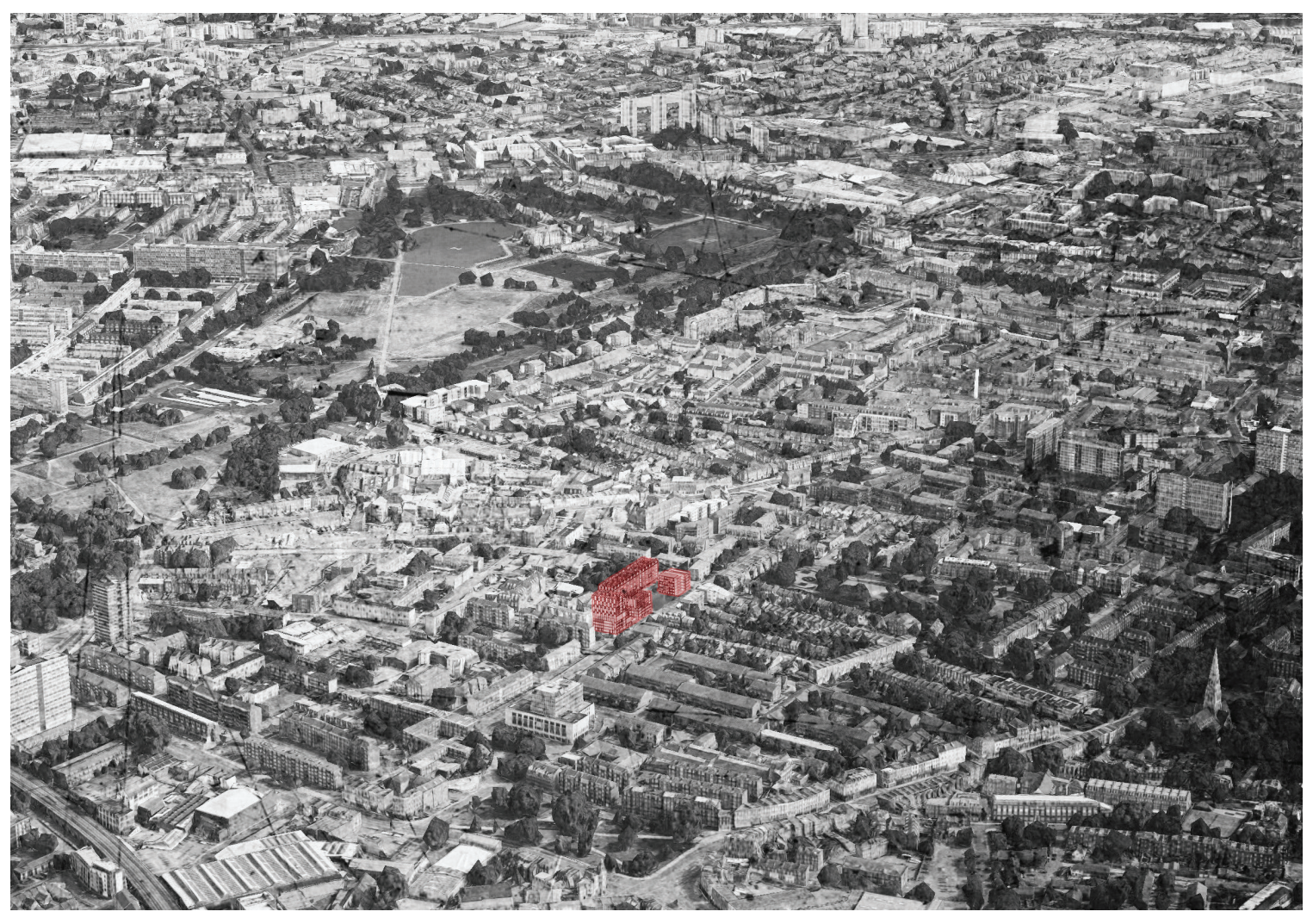

\section{EXAMPLE D: GAYHURST HOUSE, GAYHURST ROAD, LONDON, E8 3EN. TOM GARTON}

Research is centred on Gayhurst House, one of several low-rise linear blocks on the Aylesbury Estate. Constructed in 1974, the block has a reinforced concrete frame with repetitive prefabricated facade elements over 5 storeys and is scheduled for demolition. These blocks are still occupied, and the landscaping between them is generous but poorly maintained.

The proposed project aims to improve the quality of the estate by adapting and adding to the existing buildings using their concrete structure as a base to support the new lightweight timber additions. The new construction is based on LVL structural panels, clad in untreated larch and prefabricated offsite to ensure build quality and minimise construction disturbance. 


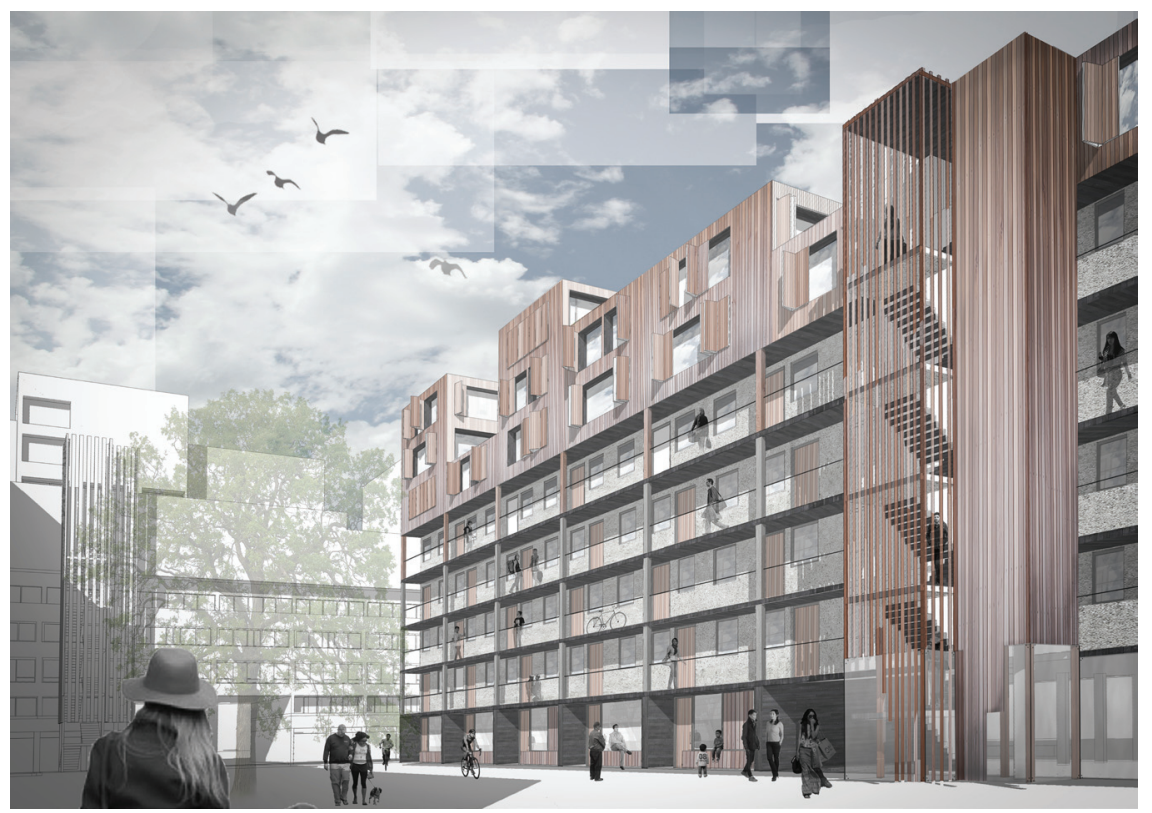

FIGURE 30.

Rendering of

the transformed

Gayhurst House.

FIGURE 31. Concept and massing diagram of the proposed extension of Gayhurst House.
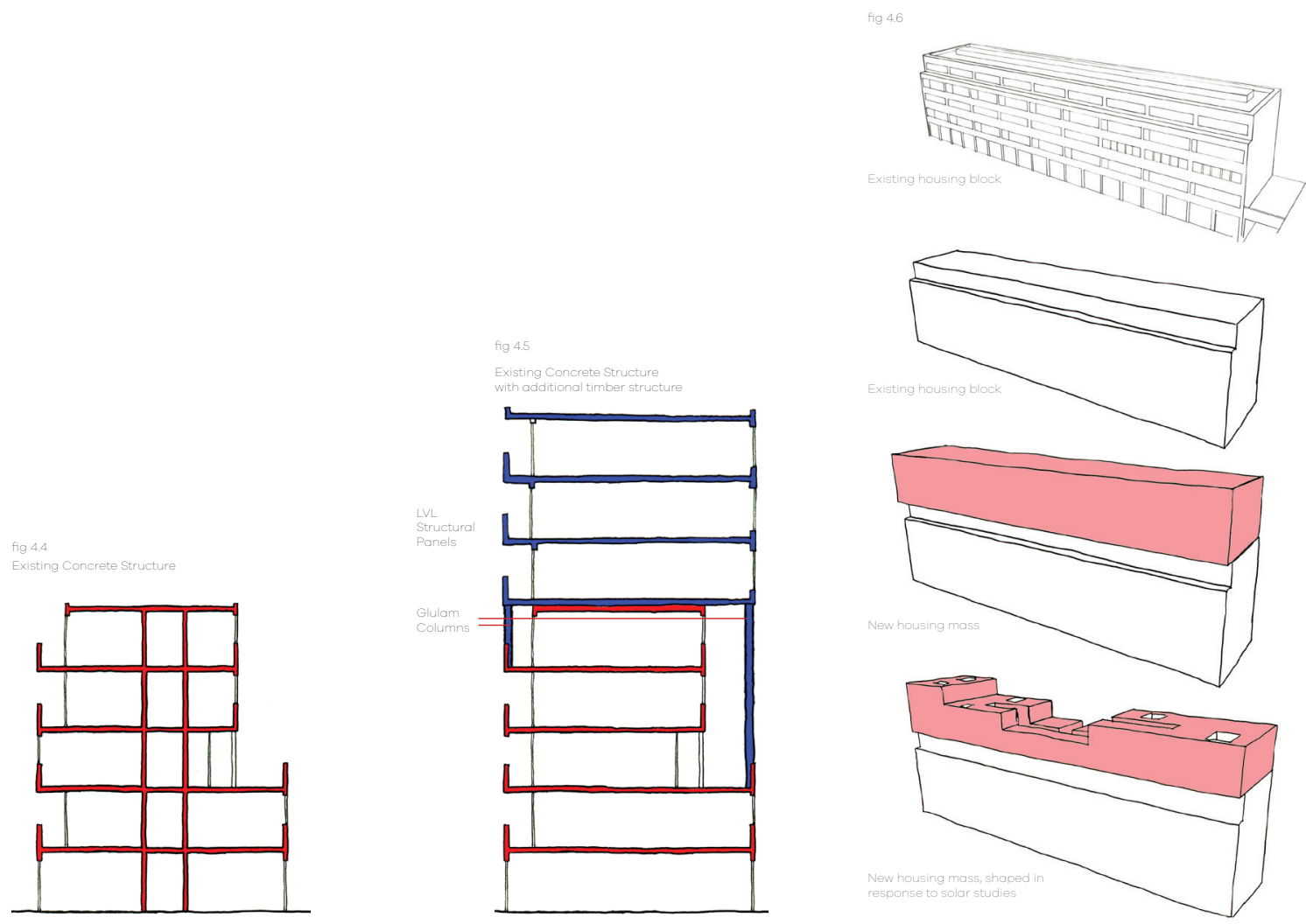
FIGURE 32. Proposed structural concept retains the existing concrete frame and is topped by lightweight engineered timber extension.

7.0 Construction Methods


Section AA

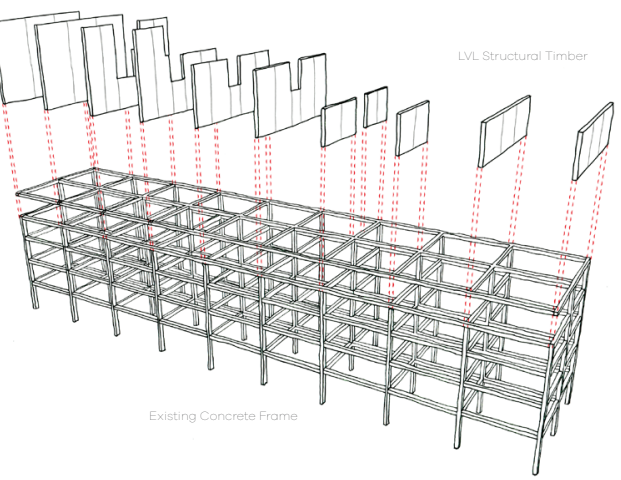

FIGURE 33. Structural detail of the new engineered timber and existing concrete frame connection.

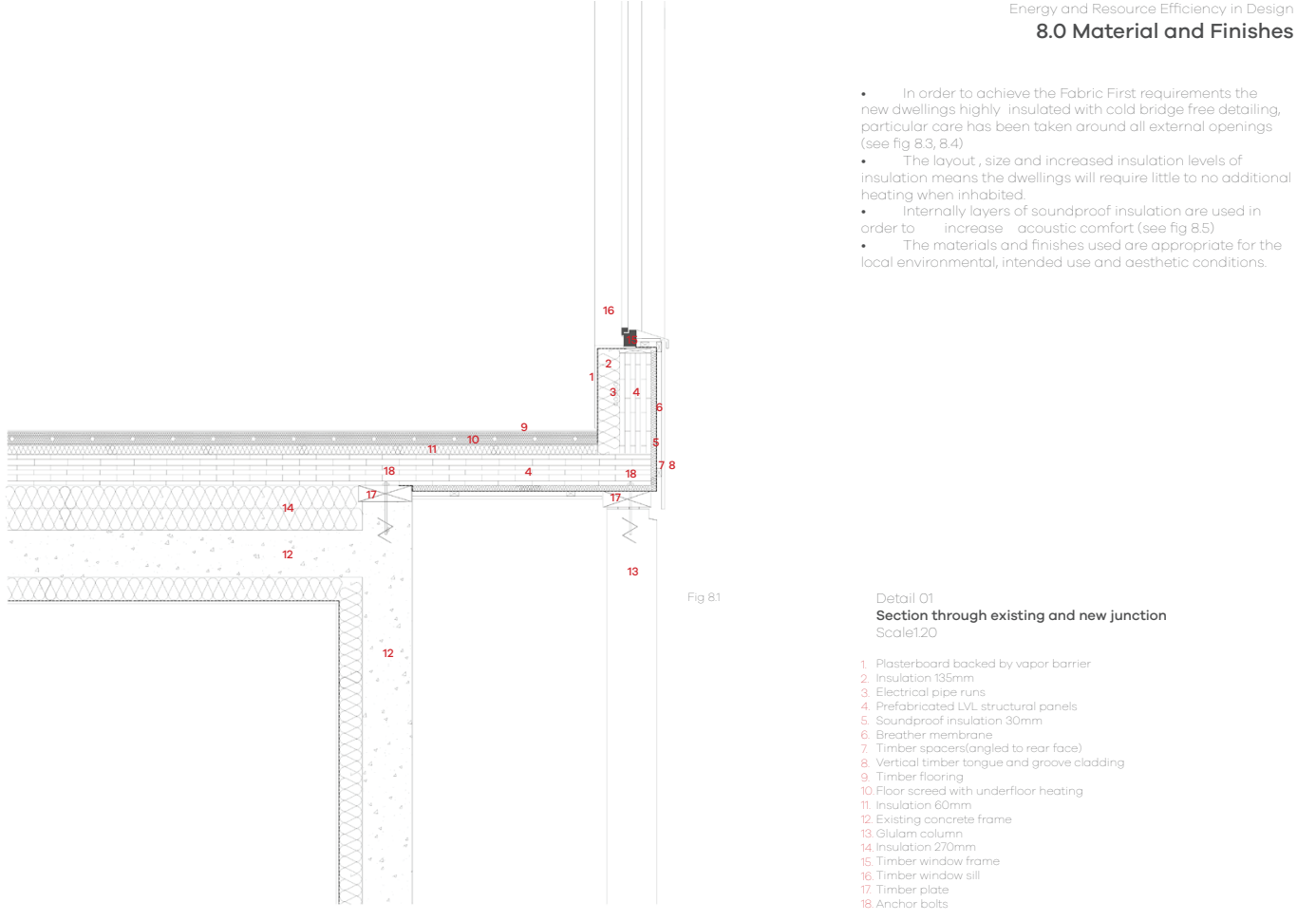


Two of the core aims for the project is to improve the relationship of the block with the public realm at ground level and create cohesion between existing and future residents through design. By extending the landscape up through and around the building and up onto the roof-scape, the proposal effectively extends the street up to the sky. Through careful design of the shared public spaces, the newly extended street provides a social thread running throughout the proposed development.

FIGURE 34. Using lightweight engineered timber construction allows the existing building to be extended without resorting to environmentally wasteful demolition.

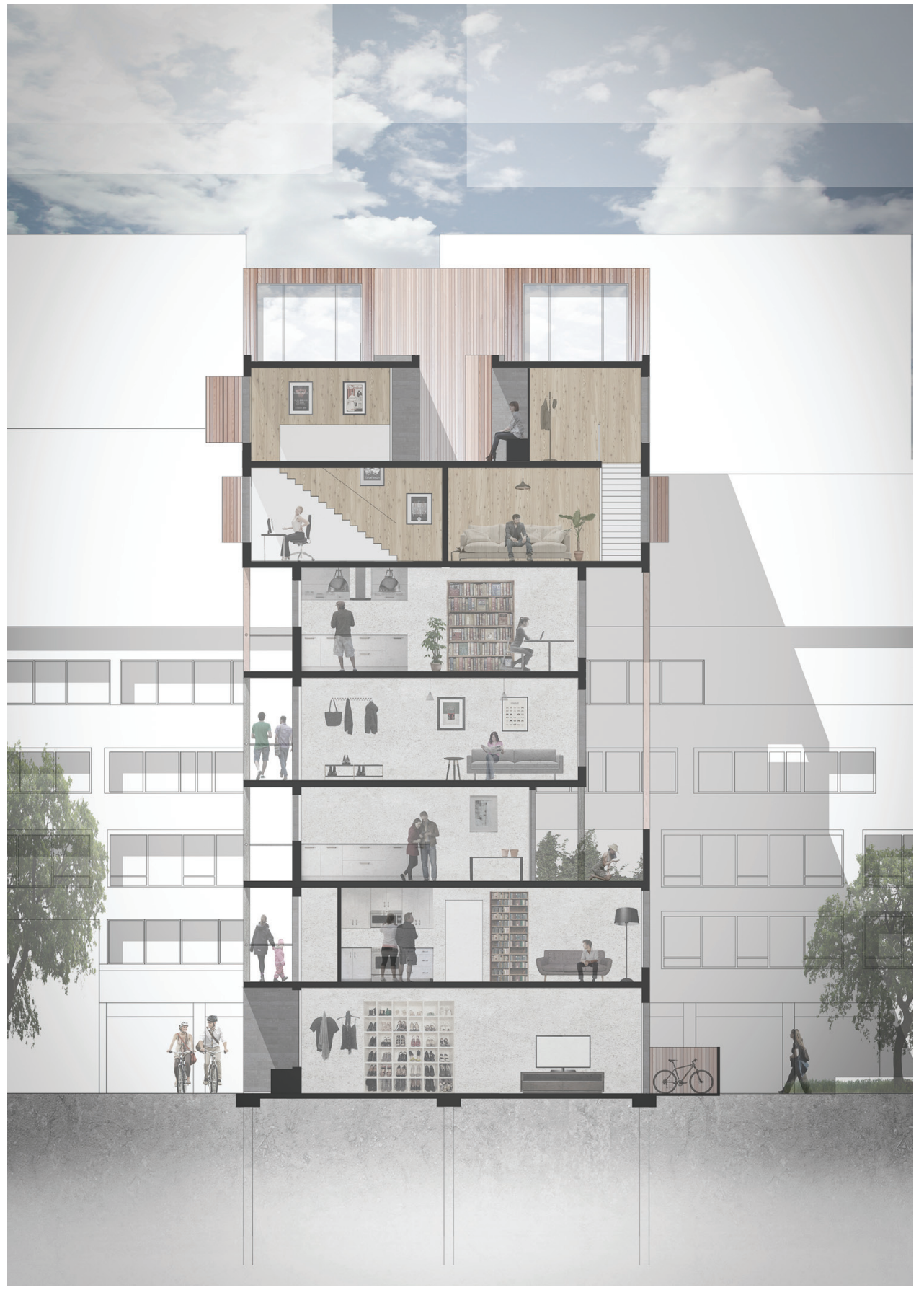


This concept offers an alternative vision for regenerating the Aylesbury Estate that does not resort to demolition that requires the displacement of the existing community. Across Britain there are many estates facing the same fate, and this projects serves as a prototype example of how the existing fabric can be reused, improved and extended to create a more sustainable and socially responsive built environment whilst providing much needed additional social housing.

FIGURE 35. The prototype redevelopment Gayhurst House can be deployed on several of the other low-rise linear blocks on the Aylesbury Estate. All images of the Gayhurst House proposals courtesy of Tom Garton.

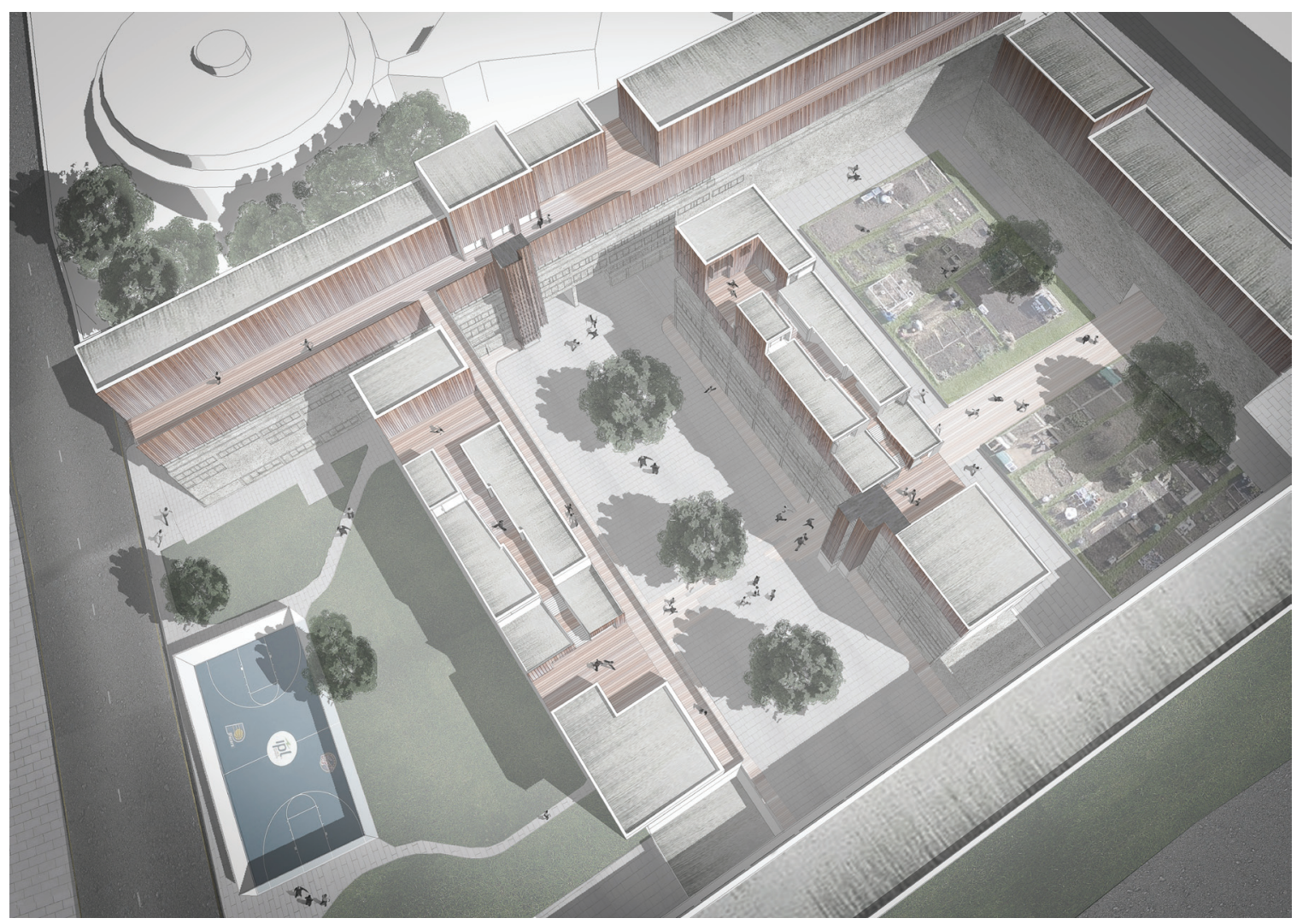

\section{CONCLUSION:}

As demonstrated, a 'rejuvenated city' based on a more productive, socially robust, and genuinely sustainable model is economically feasible and achievable in real world conditions which can allow the city to expand both in density and diversity. The above prototypes demonstrate that this is possible as a desirable social option and more cost effective than the commonly practiced development model. Not only can we build on established communities, we can also make the city a place of production, reducing the need to consume vast quantities of food, goods and energy from increasingly distant markets. These prototypes also illustrate how future development can be "low carbon" and "low energy" causing minimal impact on total $\mathrm{CO}_{2}$ emissions through the use of timber as a sequestering building material that doubles as a carbon store. Timber, being a comparatively lightweight structural material, allows for 
increased accommodation on development sites that build upon existing structures, quicker erection, with minimal disturbance to the neighbourhood. The potential of LVL and CLT has yet to be fully exploited as an innovative architectural technology and through increased use could help society address the problems we face due to population growth and global warming in the necessary expansion of cities. The use of timber in urban construction has numerous advantages in supply, transportation, ease of construction, and ultimately as a sequestering product, as it acts as a carbon store rather than a carbon emitter.

\section{REFERENCES:}

Intro. (a)www.metsawood.com/global/Campaigns/planb/cases/wooden-skyscraper/Pages/wooden-empirestate-building.aspx

(3) Hall, Suzanne, 2013, 'Super-diverse Street: A 'trans-ethnography' across migrant localities', Ethnic and Racial Studies, Online. pp. 1-14. ISBN: 978-0-415-68865-9

(4) Ref. http://drmm.co.uk/projects/view.php?p=wood-blocks

(5) Ref: http://waughthistleton.com/murray-grove

(6) The Self Build Book, how to enjoy designing and building your own home, John Broome \& Brian Richardson, Green Books, 1991 ISBN: 18700098234 